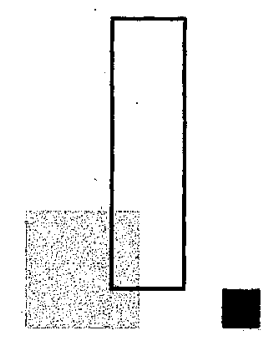

\title{
Ciudad Sanitaria
}

\author{
de la \\ Seguridad Social \\ la Fe \\ Valencia - ESPAÑA \\ JUAN DE ZABALA Y LAFORA + , \\ FERNANDO FLÓREZ PLAZA, \\ arquitectos \\ colaborador en la Dirección: \\ JAVIER PICABEA CERVINO, \\ arquitecto
}

143-57 


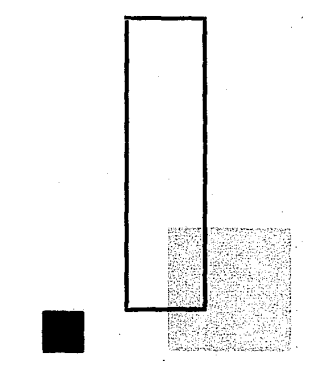

\section{sinopsis}

Este complejo sanitario, construido con precisión y notable rapidez, resuelve de manera rotunda toda una serie de urgentes necesidades planteadas en la provincia. Se recogen en él todas las experiencias anteriores en centros similares del país, con incorporación de todo tipo de adelantos técnicos, de materiales y de instalaciones que, año tras año, se van perfeccionando de forma acelerada en este tipo de edificios.

En la redacción del proyecto se han tenido muy en cuenta, para resolverlas acertadamente, las premisas esenciales planteadas de funcionalidad, investigación y enseñanza.

El programa completo, con unas 1.100 camas para enfermos abarca siete partes bien diferenciadas: Hospital Residencia general; Centro de rehabilitación; Maternidad; Hospital infantil; Escuela de enfermeras; Laboratorios centrales, de investigación y cirugía experimental y Servicios generales (central térmica, tratamiento de aguas, lavandería, incineración, mortuorio, etc.).

Se ha estudiado cuidadosamente la habitación tipo, tendiendo a la máxima flexibilidad de ocupación mínimo relativo de coste, máximo confort, recorridos ponderados de enfermeras, reducción de promiscuidad, etc., agrupando racionalmente el número de ellas a servir por un mismo núcleo de servicios generales.

En tres números sucesivos de INFORMES se desarrolla, de forma suficientemente expresiva, este importante conjunto edificado, que pone de manifiesto el esfuerzo ingente de la Seguridad Social española para ponerse en primera línea mundial en este terreno de la Asistencia sanitaria. 


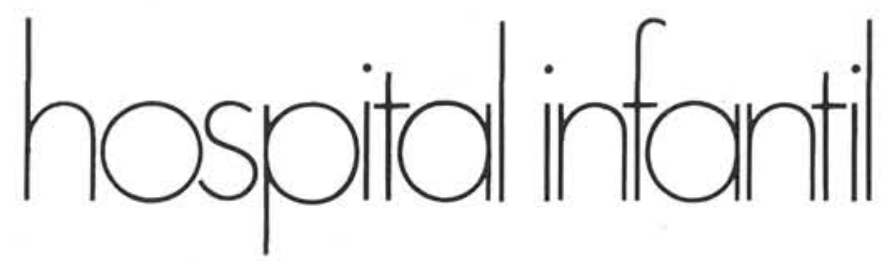

La "planta general" del edificio está formada por cuatro rectángulos separados entre sí, con sus fachadas en línea, dos a dos y unidos entre sí por el centro de sus lados.

El edificio consta de cinco plantas como las descritas; en donde las dos últimas, los rectángulos, son mayores y vuelan sobre las inferiores.

La disposición clínica de los Servicios se detalla a continuación. Se ha procurado, dentro de las características tan particulares de los servicios aquí instalados, darle la mayor elasticidad posible a las unidades de enfermería.

\section{planta semisótano}

79 prematuros, 17 para clasificación y 34 indiscriminados.

\section{planta primera}

26 infecciosos, 30 escolares y 24 camas de cuidados intensivos.

\section{planta segunda}

38 camas de niños con madre y 99 lactantes.

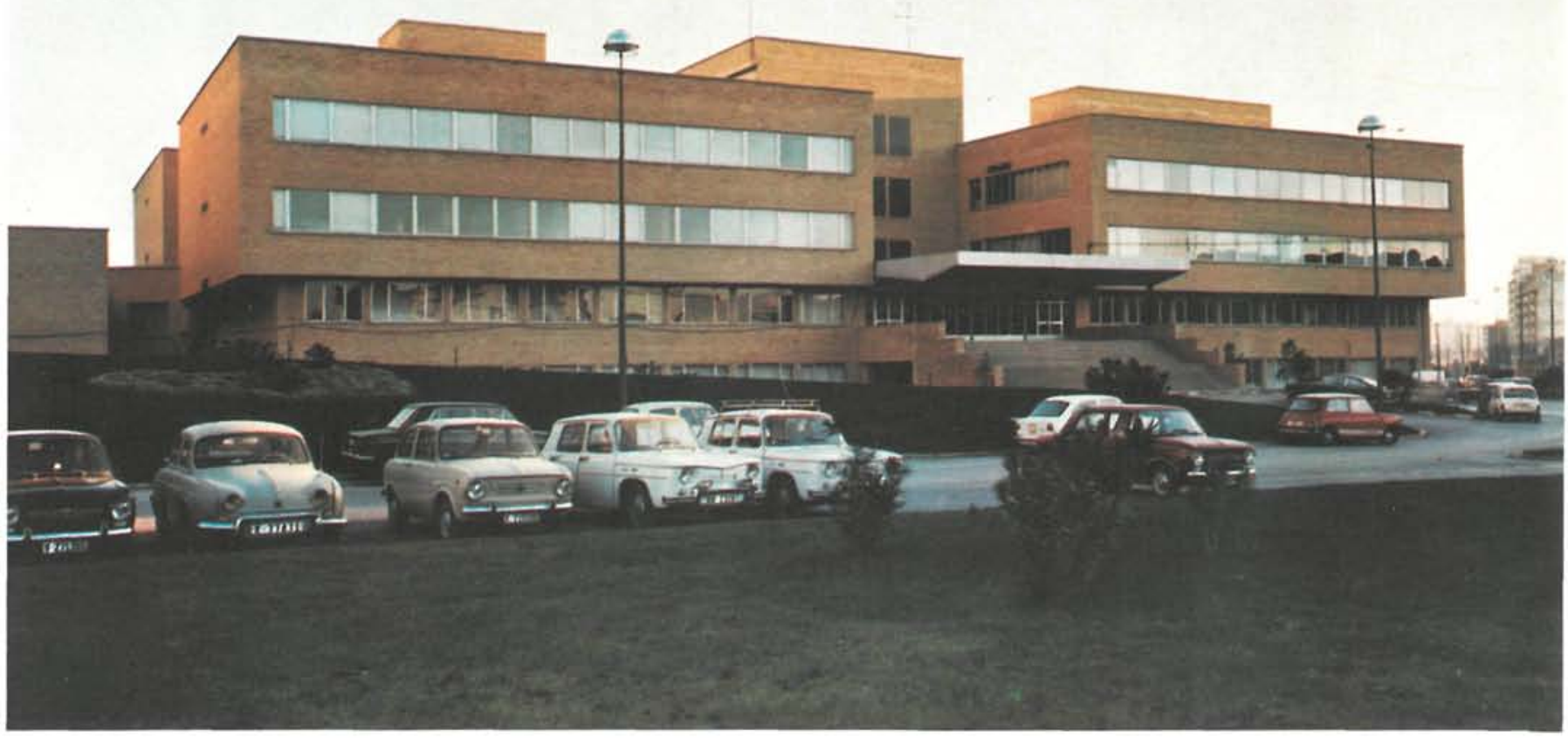



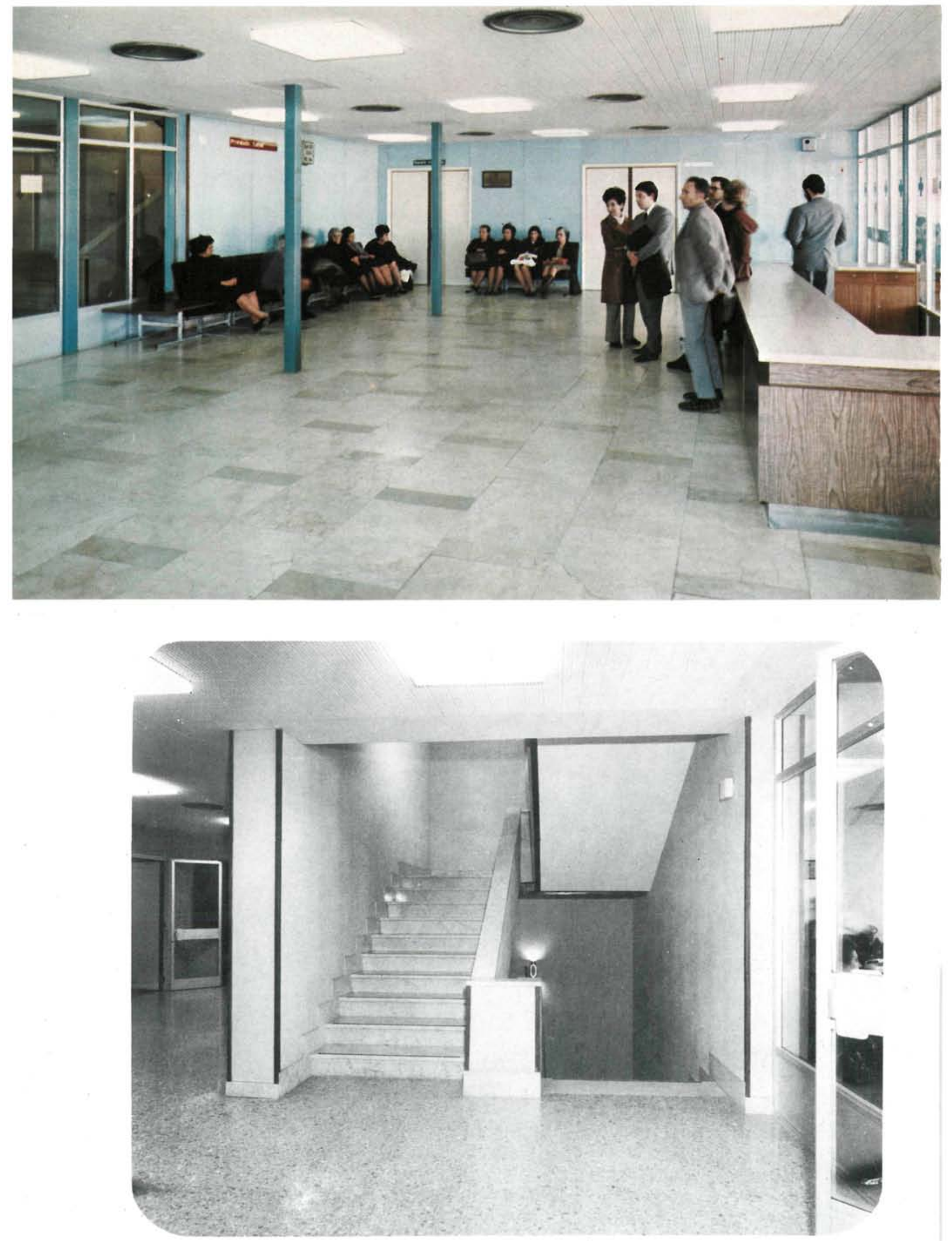


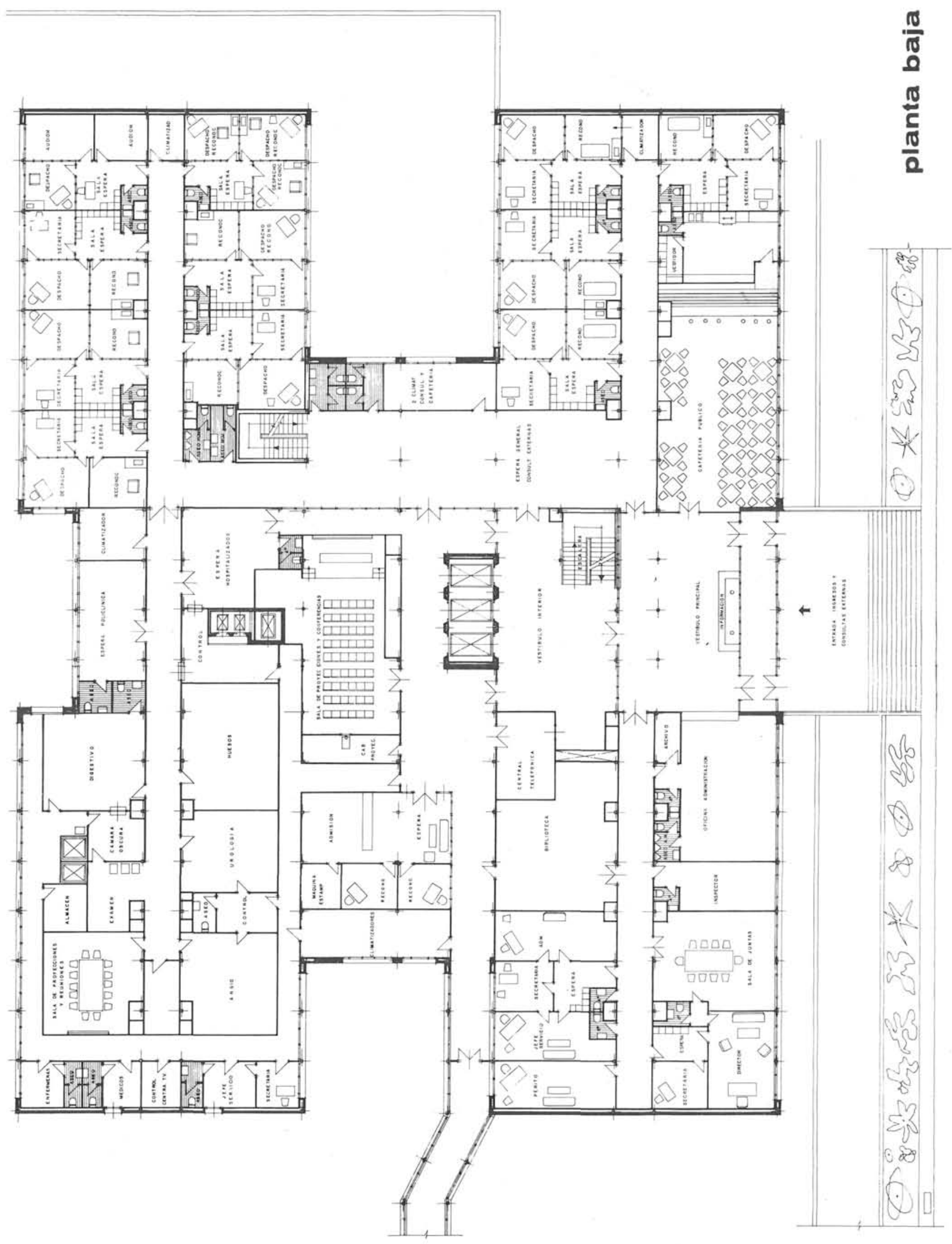




\section{planta sótano}

Destinada a servicios está incluida en ella la Central de Esterilización, que ocupa uno de los cuatro rectángulos. En el segundo se sitúa la cocina, que se divide en cocina de adultos e infantil con los almacenes y frigoríficos necesarios; en el tercero están los vestuarios de personal, y en el cuarto, espacios para el centro de transformación, cuadros y cuarto de climatizadores. En el centro se sitúan los almacenes, uno para ropa limpia y otro para sucia, ya que la Ciudad Sanitaria cuenta con lavadero centralizado y la cafetería de personal.

\section{planta semisótano}

Esta planta, que ya es de enfermería, está distribuida en cuatro rectángulos: el primero contiene el "servicio de prematuros"; el segundo aloja los laboratorios, que se extienden hasta el centro, donde se han colocado la espera, la recogida de muestras y los servicios de electroterapia y poligrafía; en el tercero hay una enfermería de indiscriminados, y en el cuarto, con el resto del bloque central, están la urgencia, con un quirófano y sus correspondientes elementos auxiliares. Es en esta planta donde existe un paso de unión con el edificio.

puesto de control circulación interior
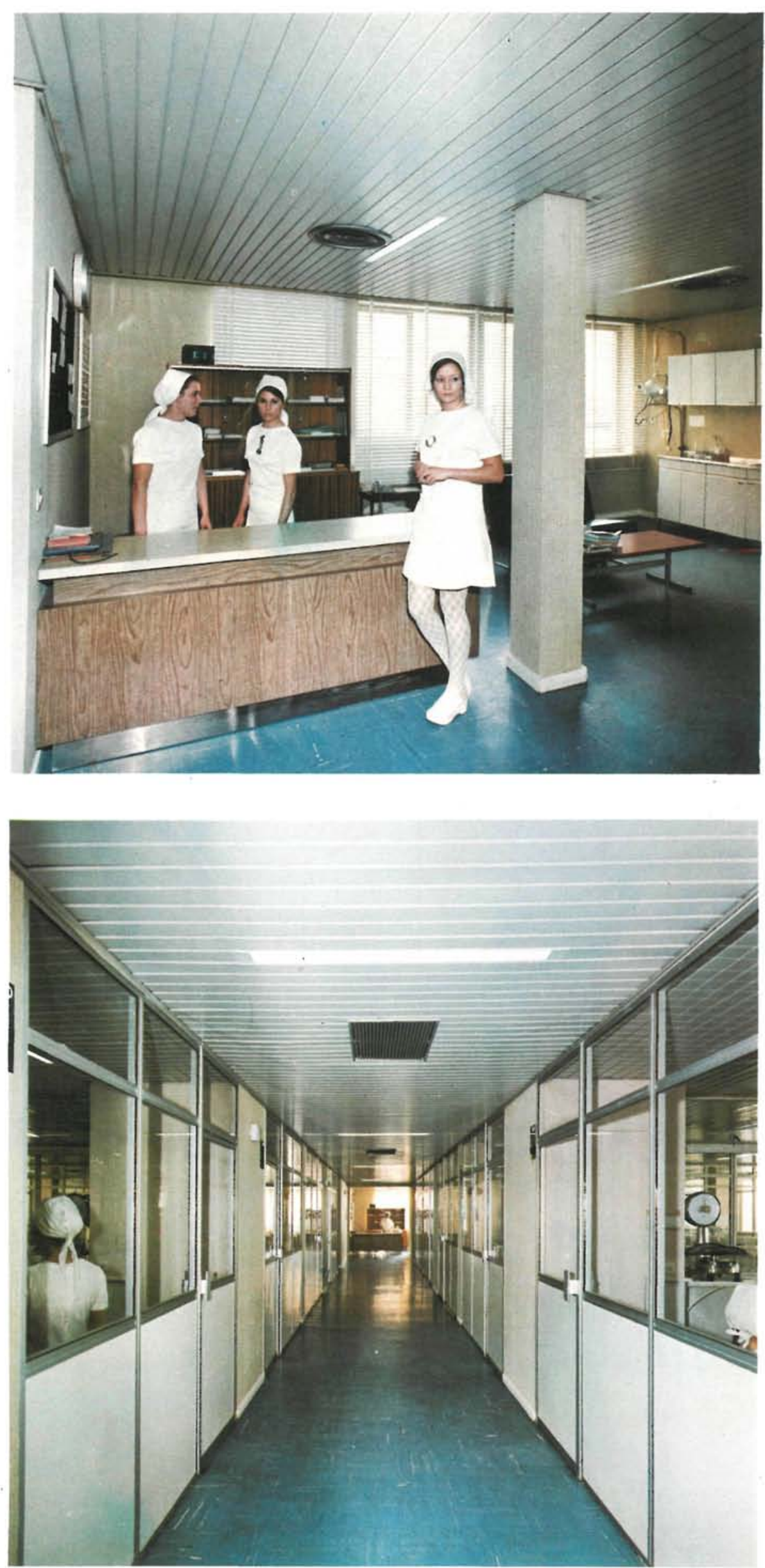


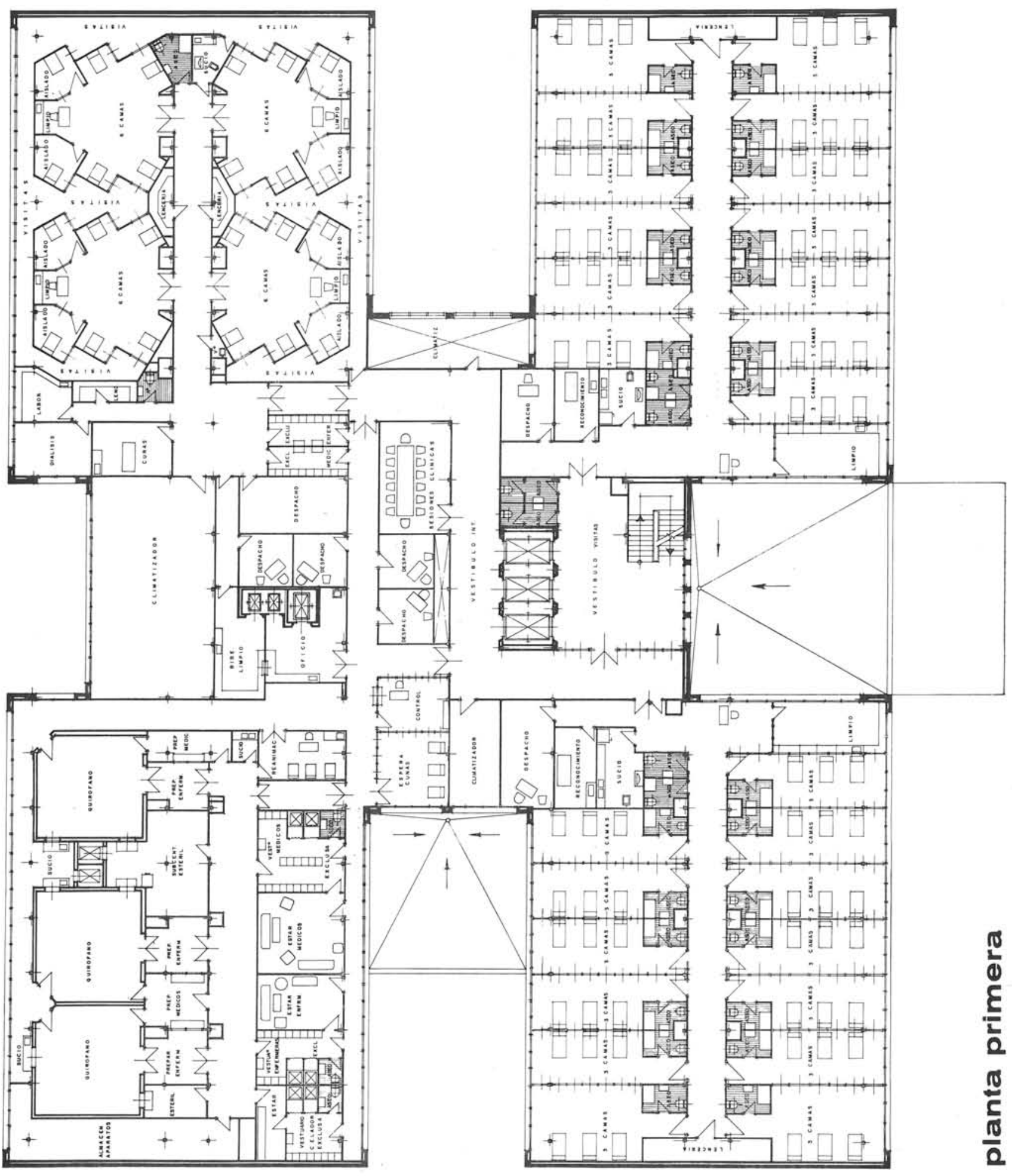




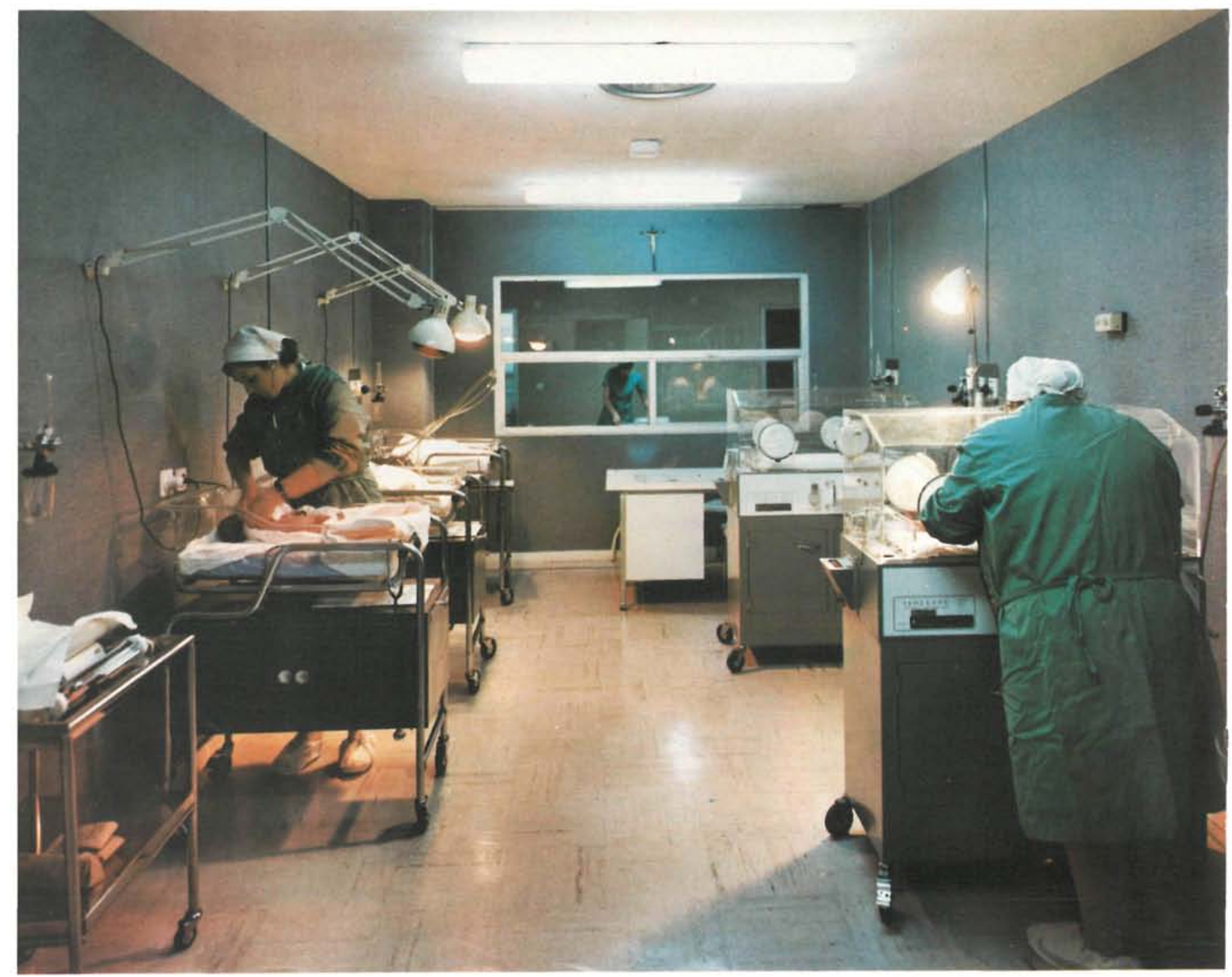

\section{planta baja}

En dos de los rectángulos se hallan las consultas externas, teniendo uno de ellos, además, la cafetería de público. En esta planta está situado el acceso principal al edificio.

Los otros dos rectángulos quedan ocupados por el "servicio de radiologían, la farmacia, oficinas de admisión, archivo de historias clínicas, biblioteca y administración.

prematuros

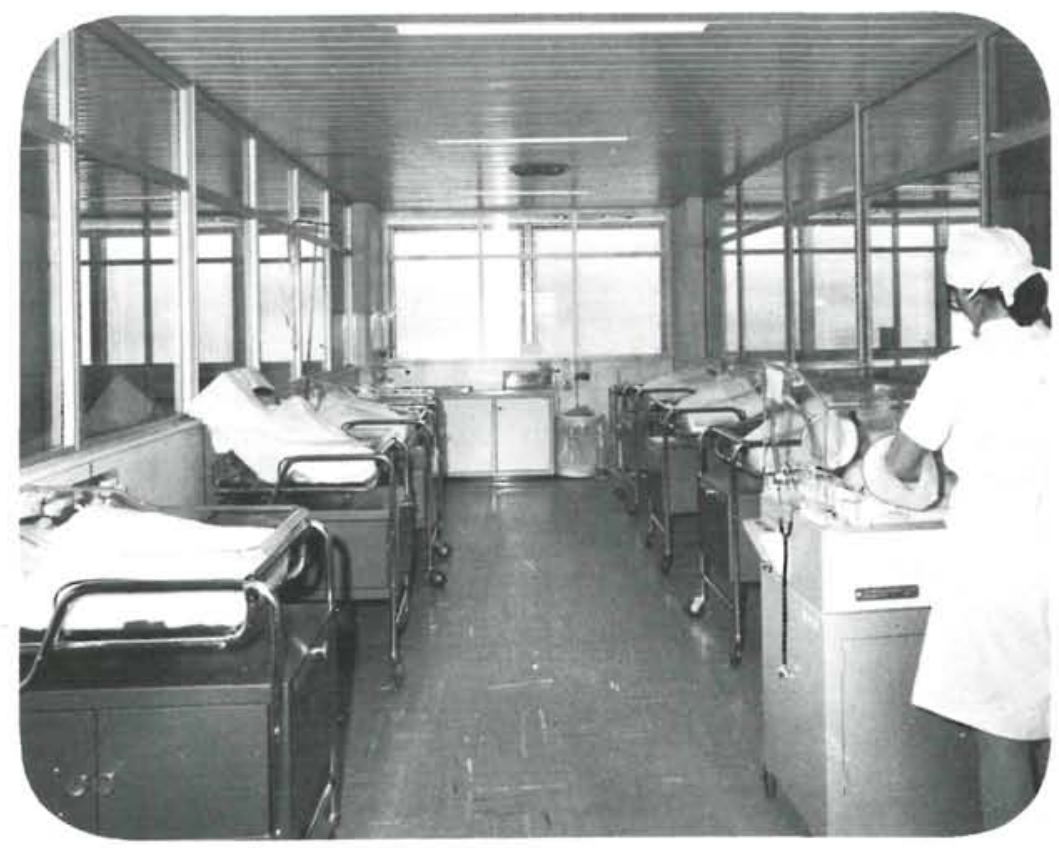




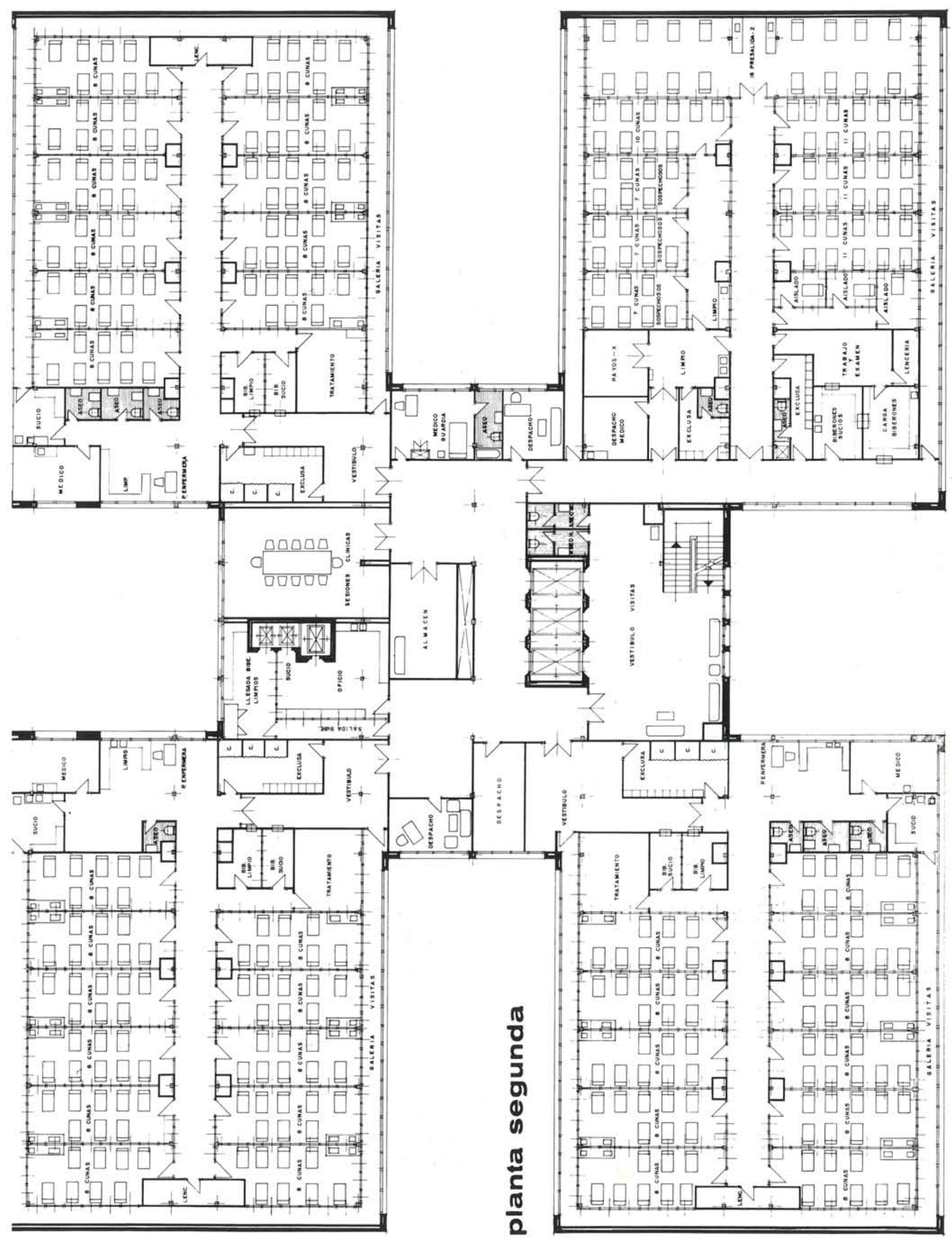



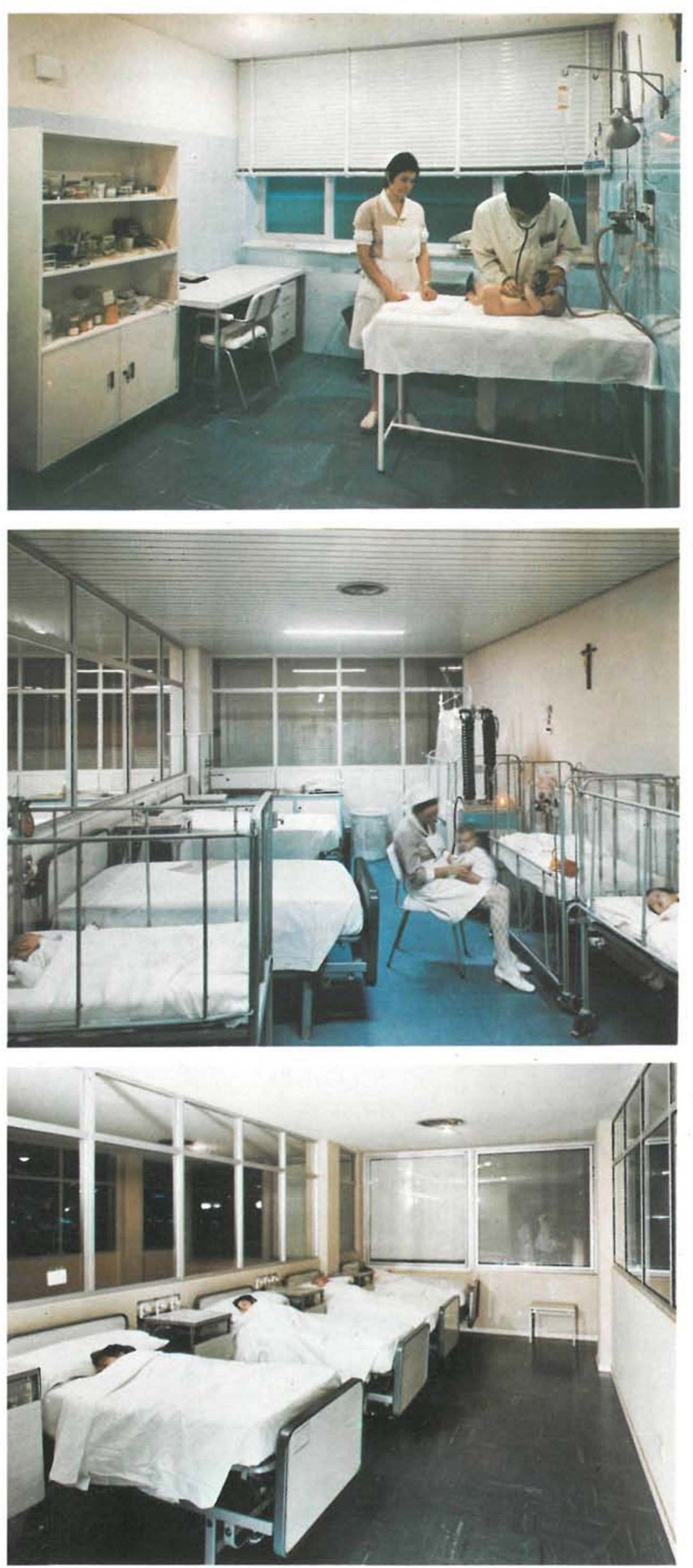

\section{planta primera}

Esta planta, donde ya los rectángulos son mayores, como indicábamos antes, es una planta de enfermería casi completa, ya que, salvo uno de los rectángulos, en los que situamos tres quirófanos con sus esclusas para personal, lados limpio y sucio, una subcentral de esterilización y las preparaciones de médicos y enfermos. En cada uno de los otros rectángulos hay una enfermería. La primera tiene cuatro unidades de 6 camas de cuidados intensivos, un puesto de enfermeras para cada uno y un pasillo perimetral para visitas que también existe en el resto de las enfermerías. Las otras dos están ocupadas, una por los infecciosos en cubículos de una cama y la otra por habitaciones de tres camas con aseo, para escolares.

\section{planta segunda}

Destinados los cuatro rectángulos a enfermería, tres son iguales y ocupados por una enfermería de lactantes divididos en dos zonas por un pasillo central de circulación de personal médico y cubículos de tres cunas, con los servicios de esclusas, puesto de enfermeras, reconocimiento $\mathrm{y}$ biberones.

La cuarta enfermería es una general para niños algo mayores o niños con madre. En el bloque central hay un gran oficio para la distribución de biberones y una sala de sesiones clínicas.

\section{circulación general}

Dada la disposición del edificio y su relativa poca altura, se ha creído como mejor solución para

\section{tratamientos}

pre-escolares y escolares 


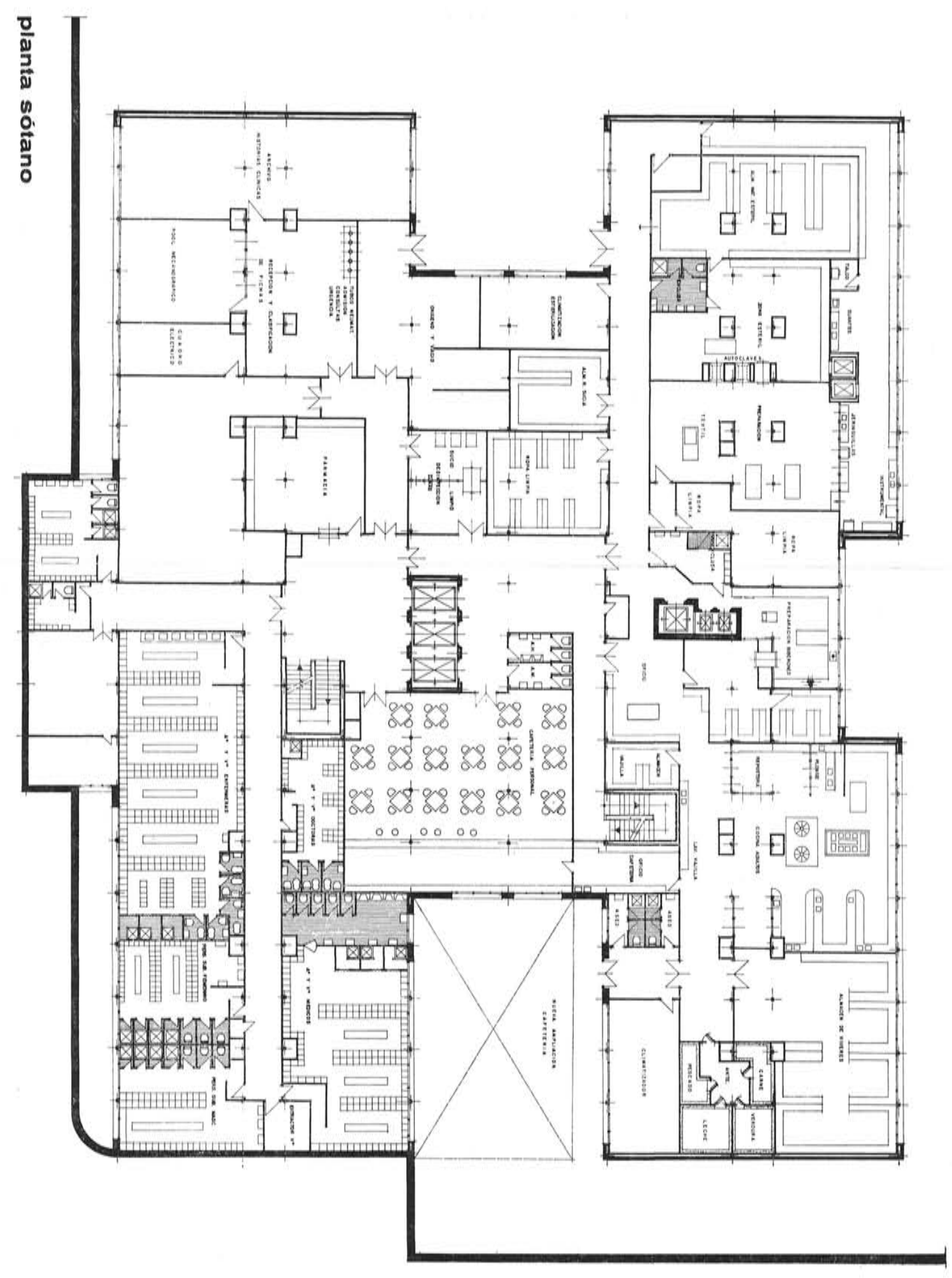




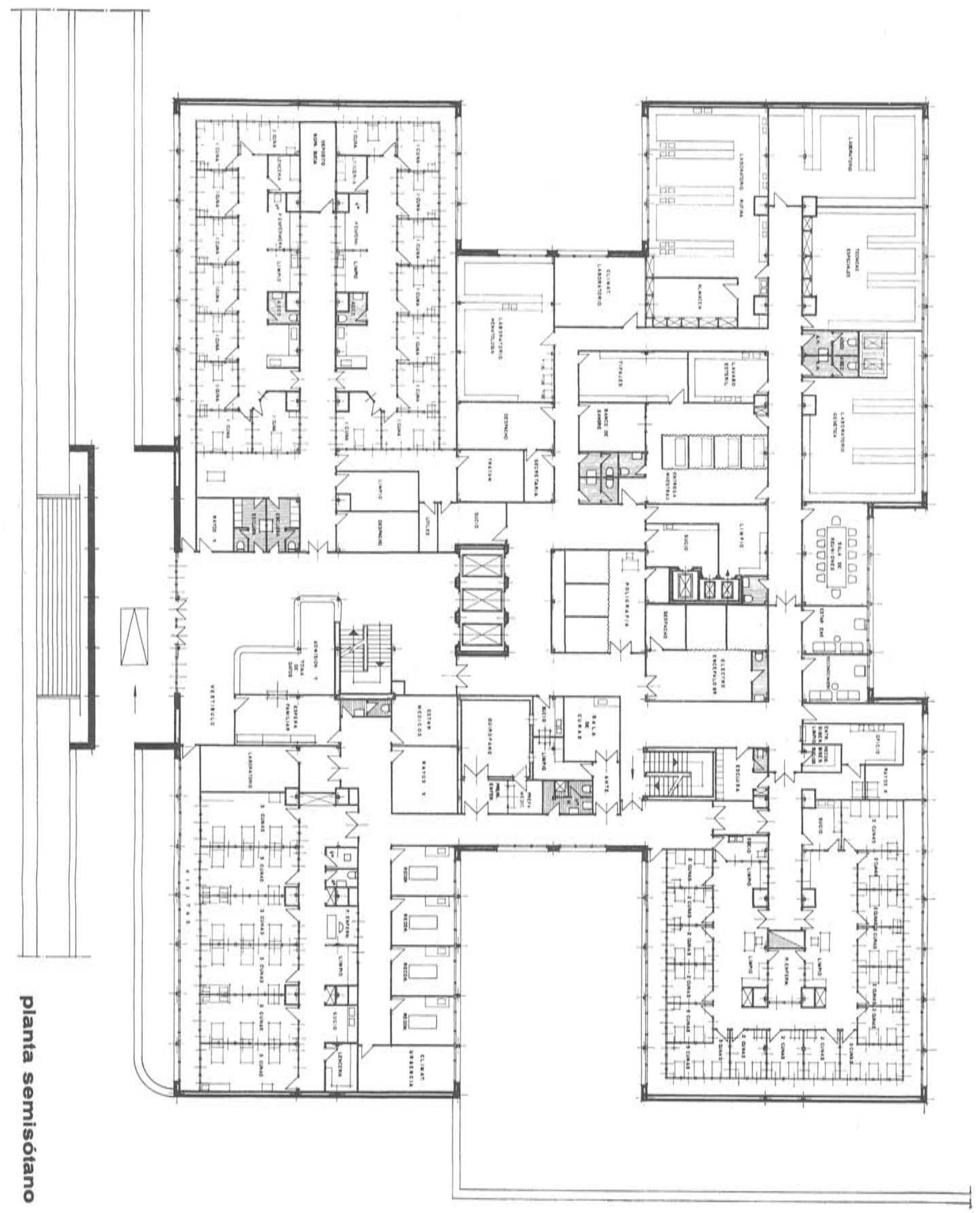


la circulación vertical, la colocación de tres grandes aparatos en el centro, con dos salidas cada uno para poder separar claramente la circulación de visitas de la interior del hospital.

Para la circulación de comidas se ha dispuesto de un montacarros para las comidas de los niños mayores y las posibles madres, y dos montabiberones: uno con acceso al lado limpio y otro al lado sucio. Para la unión de quirófanos con la central de esterilización, se han dispuesto dos montainstrumentales: uno con salida al lado estéril y otro con salida al lado sucio.

Una escalera en el núcleo central completa la instalación vertical.

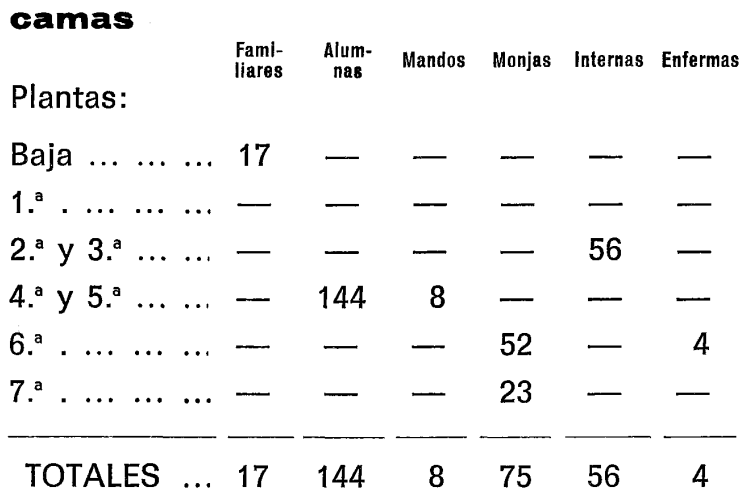

Total general: 304 camas.

\section{características generales constructivas}

paramentos exteriores

Fábricas de ladrillo a cara vista con huecos de aluminio y parasoles, según orientación.

\section{pavimentos}

Terrazos y solados de polivinilo en su mayoría. 


\section{interiores}

Formica en vestíbulos, plástico tipo Suwide en circulaciones, azulejos en tratamientos y pinturas en habitaciones de enfermos.

\section{plantas cuarta y quinta}

Contienen 144 camas para alumnas y 8 para instructoras, que se distribuyen en habitaciones de 3 camas para alumnas e individuales para las instructoras, disponiendo todas de cuarto de aseo; en la zona central: vestíbulo y sala de estar; en los laterales: cuartos destinados a lencería, lavado y plancha. El módulo habitación dispone de termos propios.

\section{planta sexta}

Esta planta se destina a la "comunidad de religiosas", con un total de 52 camas y 4 para enfermería, todas individuales; las destinadas a enfermas disponen de cuarto de aseo completo; en la zona central: vestíbulo, oficio y visitas; en sus laterales: cuartos destinados a almacén. El módulo habitación dispone de terrazas individuales.

\section{planta séptima}

Destinada también a la "comunidad de religiosas", dispone de habitaciones individuales en número de 23; habitaciones destinadas a lencería, costura y plancha, lavadero; en el ala derecha: oficio, vajilla, refectorio para 75 personas; capilla para 84 personas, y biblioteca; en la zona central: vestíbulo, recibidor, despacho de sacerdote y despacho de la superiora. El módulo habitación dispone de terrazas particulares.

\section{sorreón}

Situado en la parte central, alojará las bancadas y maquinarias de aparatos elevadores y desembarco de escalera. 

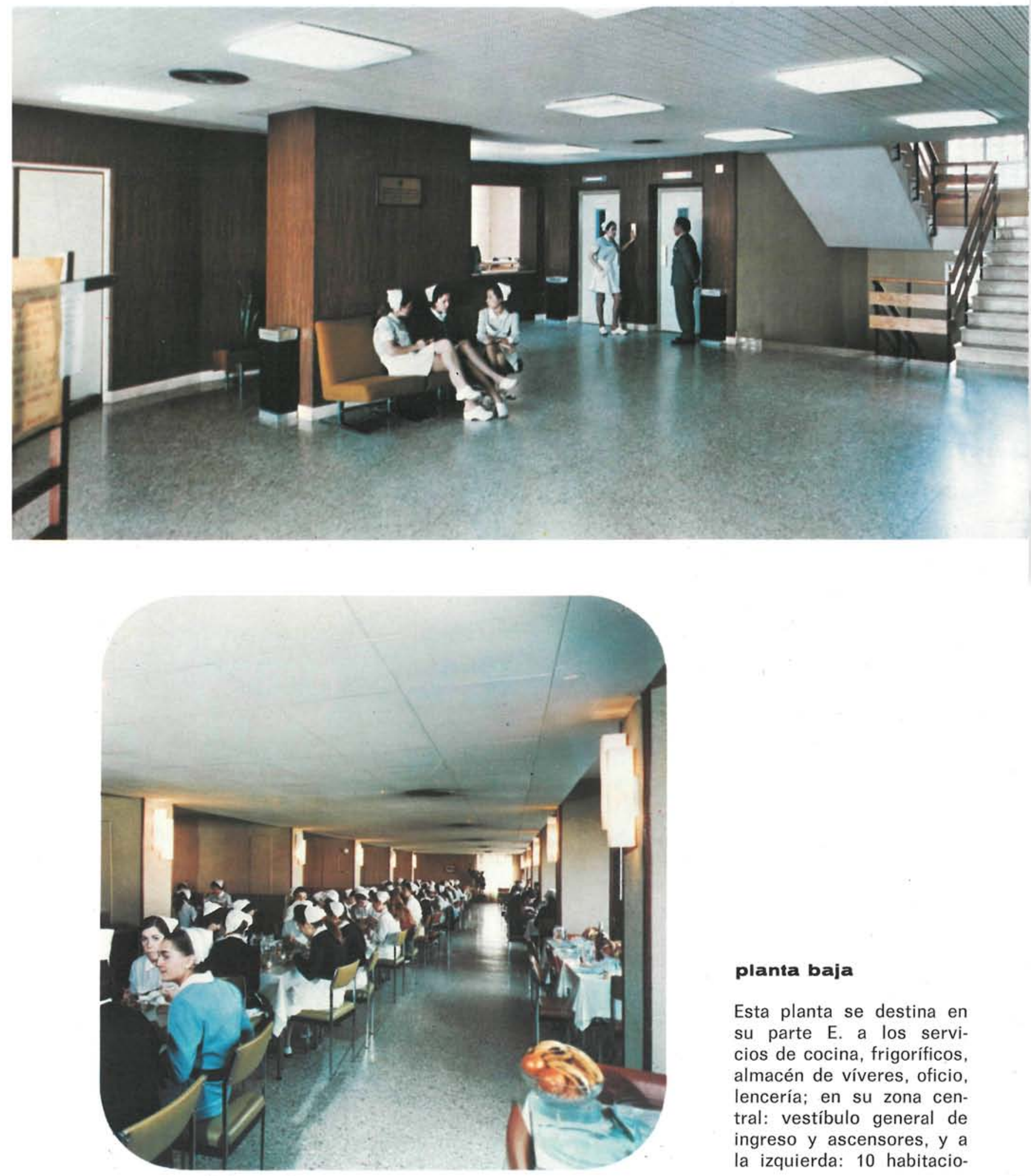

planta baja

Esta planta se destina en su parte E. a los servicios de cocina, frigoríficos, almacén de víveres, oficio, lencería; en su zona central: vestíbulo general de ingreso y ascensores, y a la izquierda: 10 habitacio- 

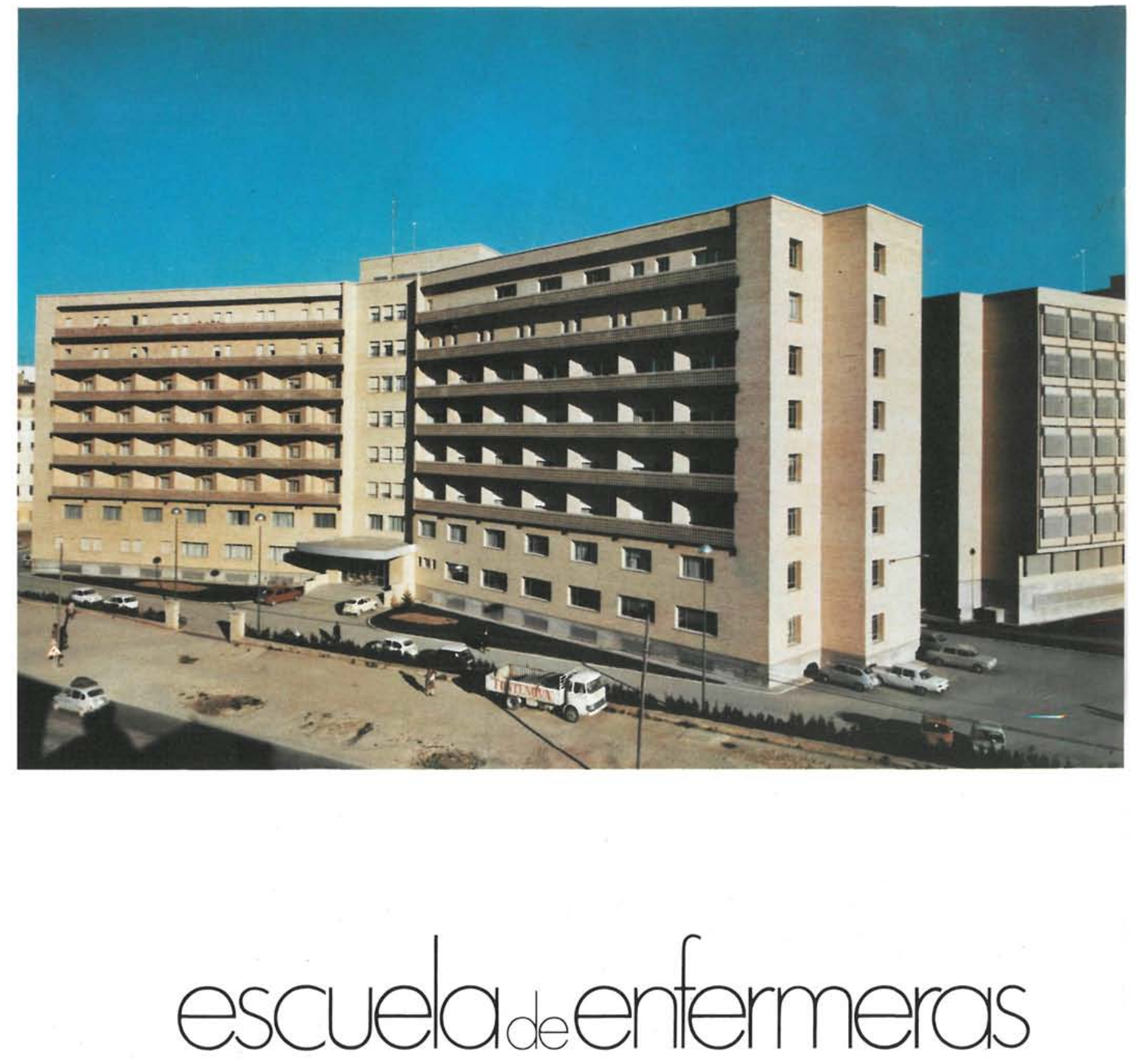

\section{distribución del edificio}

Este inmueble consta de 9 plantas, que pasamos a reseñar:

\section{planta semisótano}

Consta de: almacenes generales, vestíbulo de acceso, fosos de aparatos elevadores, cuarto de calderas, centro de transformación, cuadro general, voltabloc, almacenillo, gimnasio y aseos $\mathrm{y}$ vestuarios generales. 


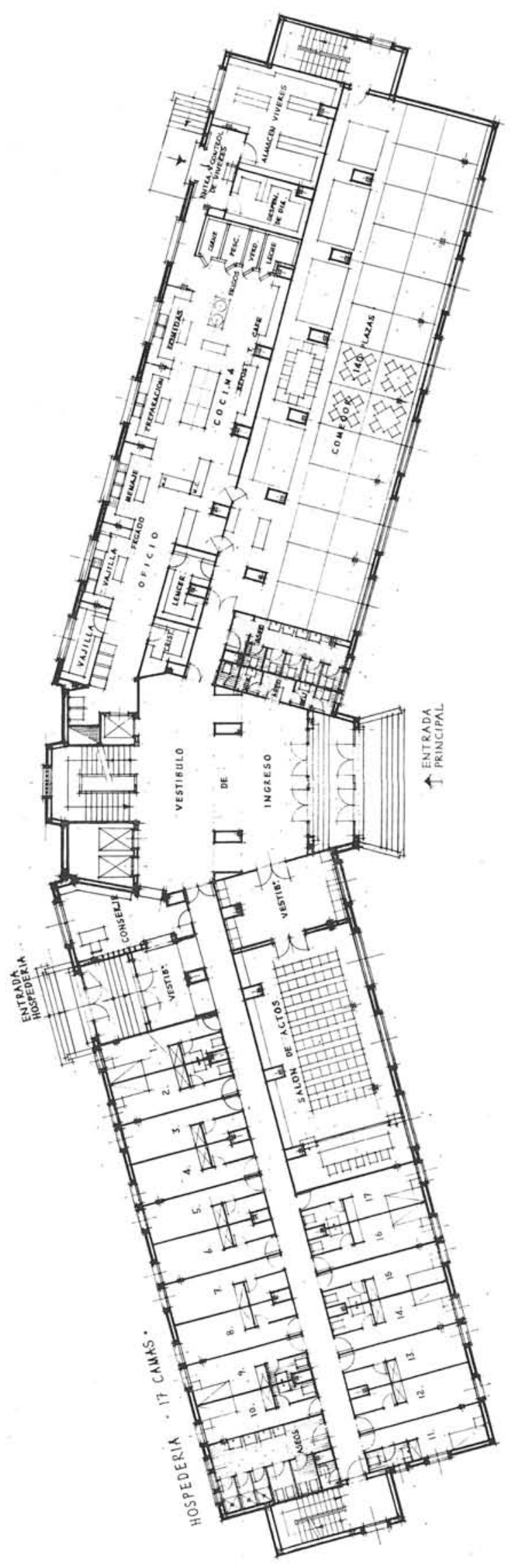

planta baja

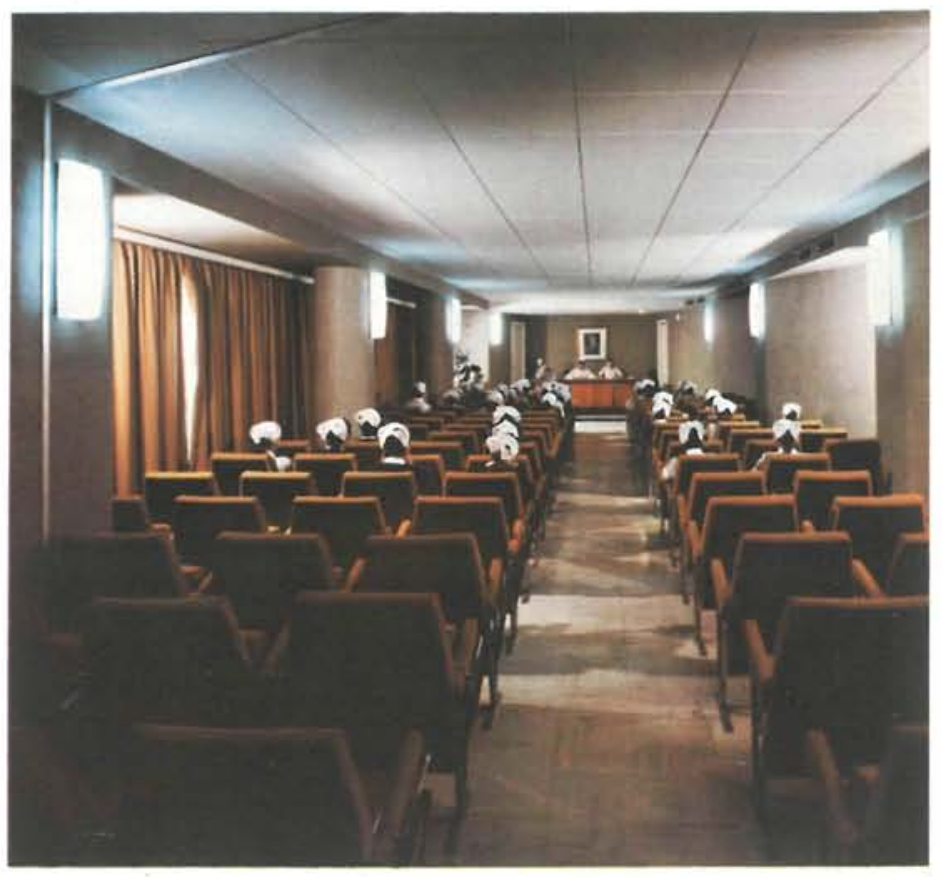

sala de conferencias

nes individuales con destino a hospedería; en la parte oeste se sitúa el comedor para 140 plazas, aseos de ambos sexos, vestíbulo y salón de actos, y siete habitaciones individuales con el mismo destino que las anteriores. 

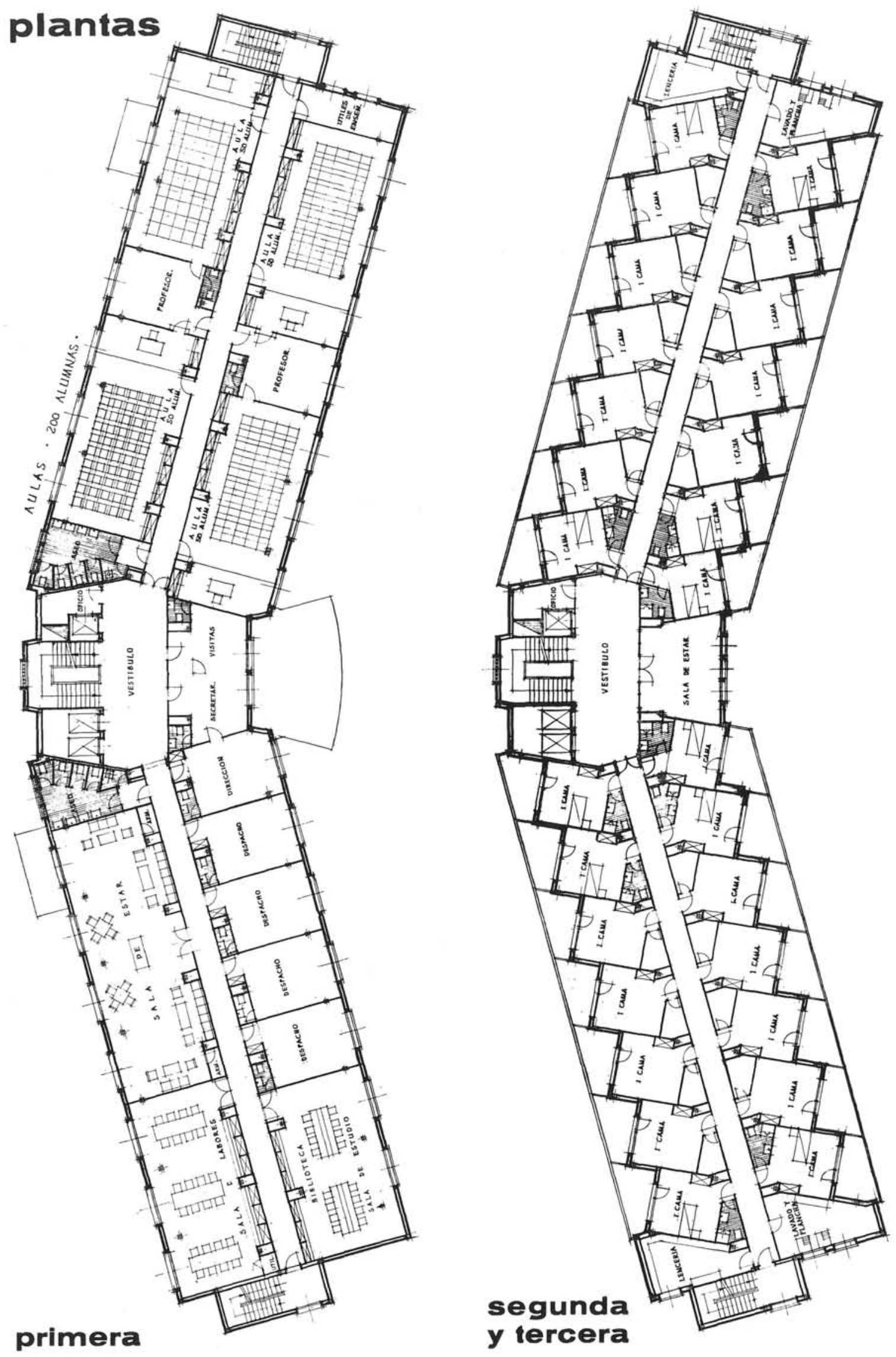


\section{planta primera}

Aloja las aulas, con capacidad para 200 alumnos, despachos de profesores, sala de estar, sala de labores, biblioteca, secretaría, dirección y despachos administrativos, aseos generales, vestíbulo central $\mathrm{y}$ ascensores.

\section{plantas segunda y tercera}

Alojan a habitaciones individuales con un total de 56 para enfermeras, todas ellas con cuarto de aseo en la habitación; dispone de cuarto para lencería, lavado y plancha; en su zona central: vestíbulo, ascensores y sala de estar. Cada módulo habitación dispone de terraza particular.

\section{instalaciones}

Todos los edificios van dotados de aire acondicionado total, a excepción de la Escuela de Enfermeras, tratada por calefacción y ventilación.

Una central térmica de agua sobrecalentada a $180^{\circ} \mathrm{C}$ con 14.000 .000 de kilocalorías, abastece de agua caliente para uso doméstico y calefacción a todo el complejo.

Los ascensores son de tensión variable con velocidades de $1,50 \mathrm{~m}^{3}$.

La lavandería tiene una capacidad de $7 \mathrm{t}$ de ropa diaria.

aula, demostraciones y sala de espera
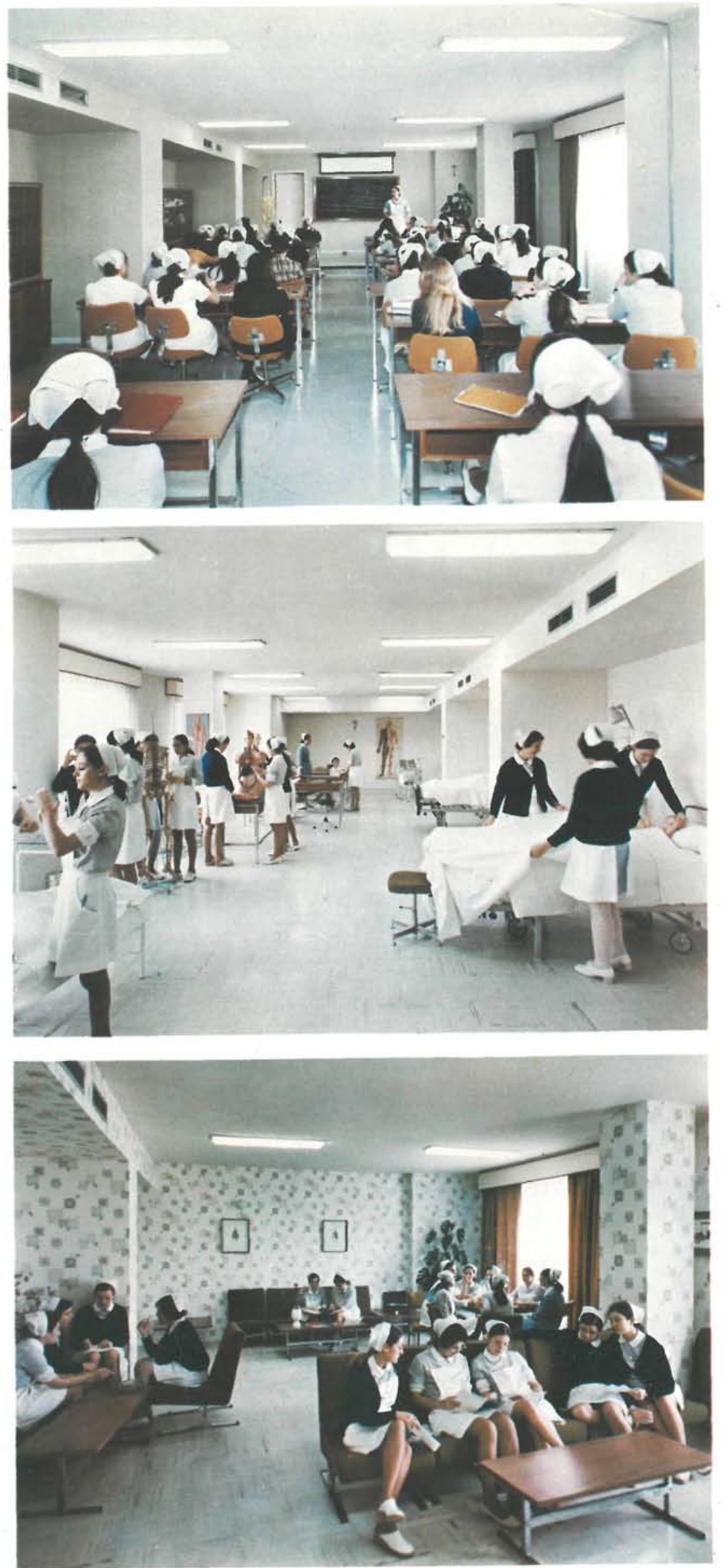

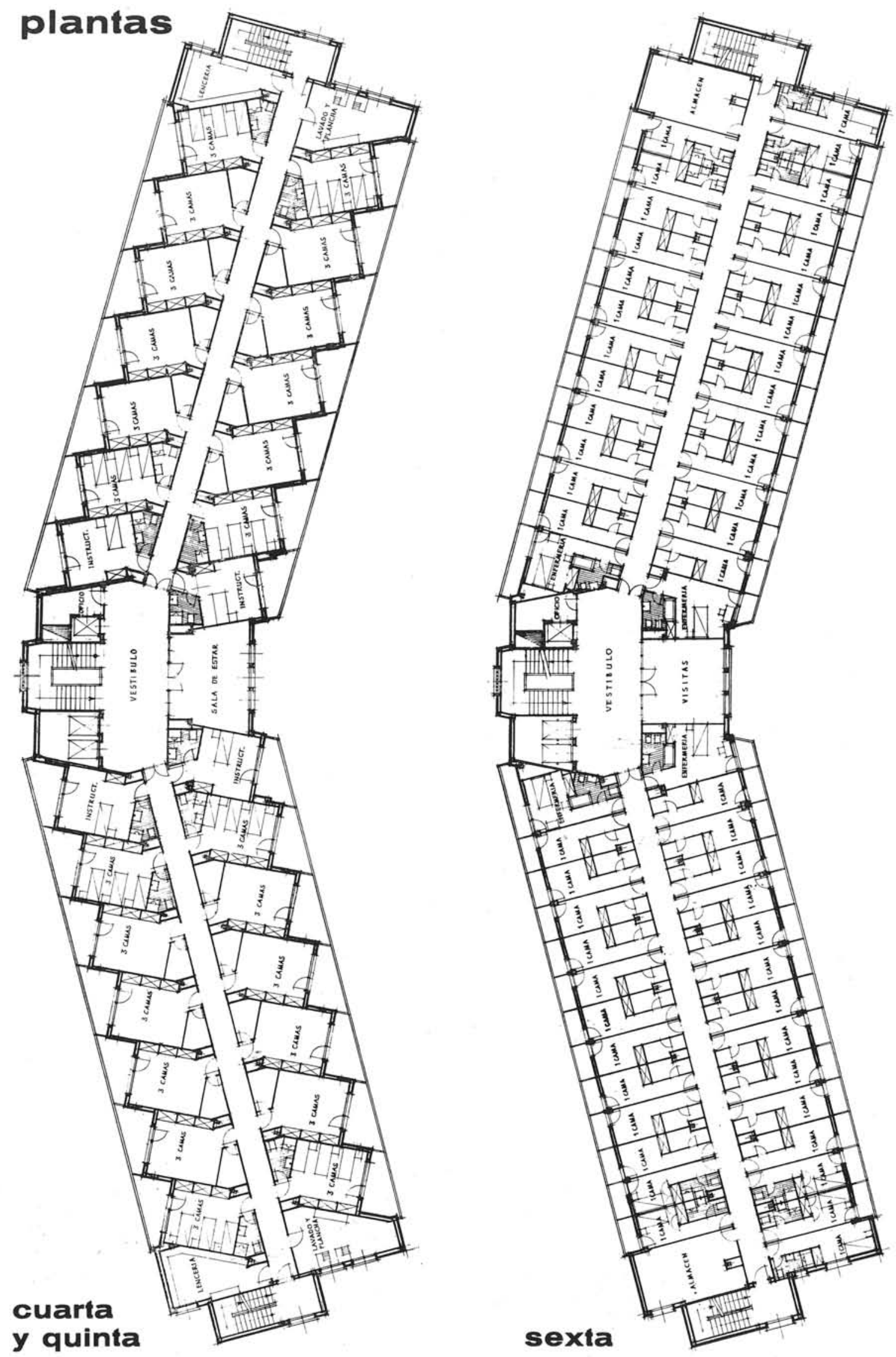


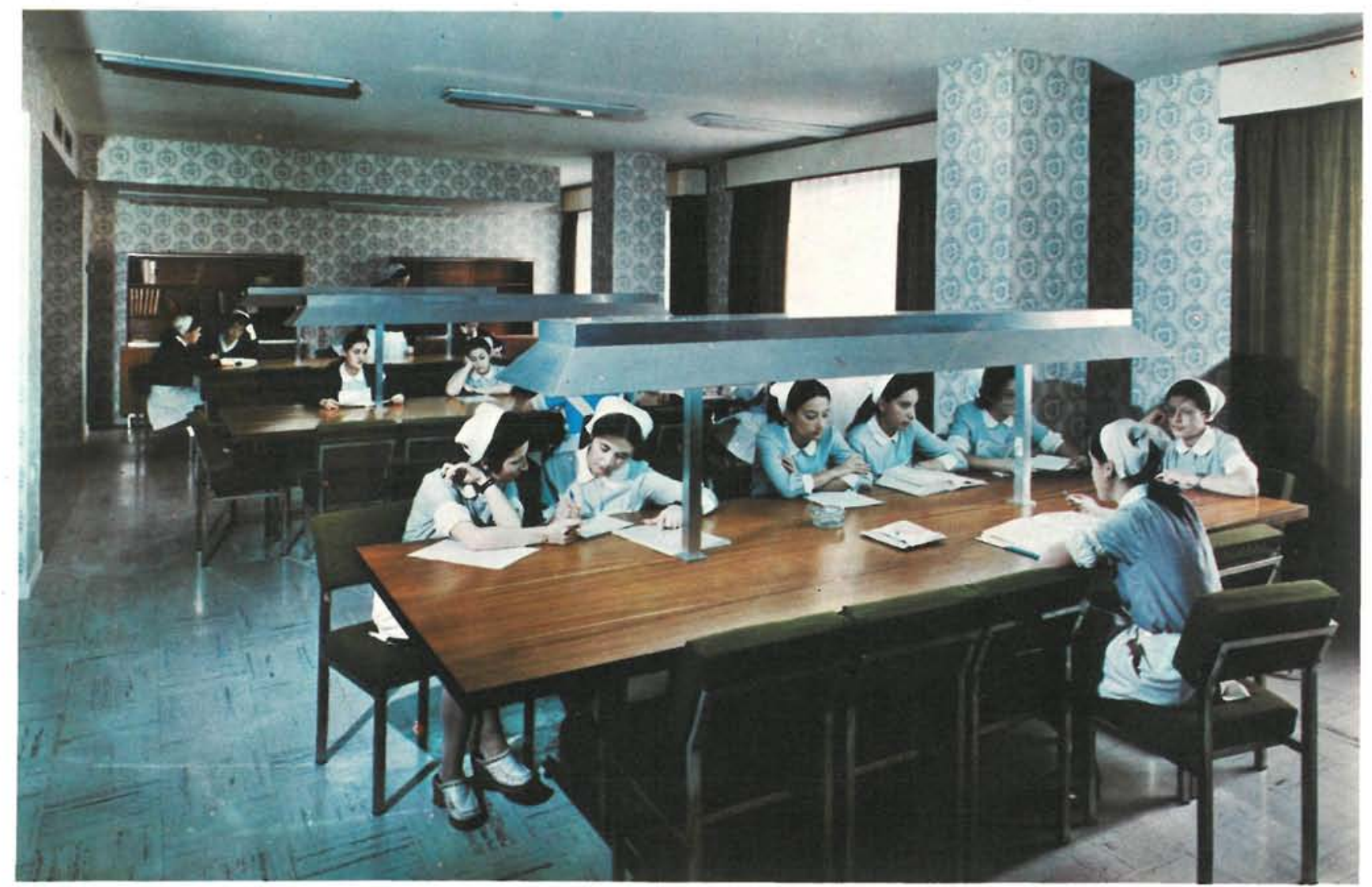

biblioteca

\section{dormitorio}

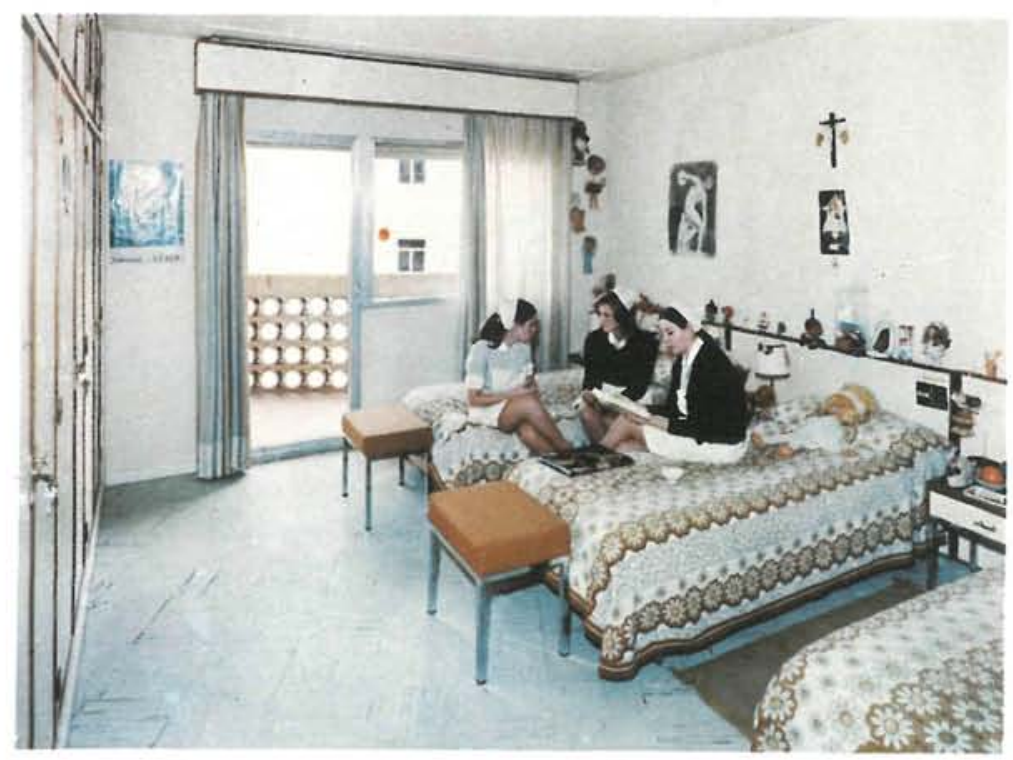

Todos los edificios llevan estación transformadora para pasar de la acometida en alta tensión a las redes de $220 / 380$ voltios.

\section{conclusiones finales}

Como datos interesantes destacables y que han sido comentados en muchos países, merece la pena señalar dos características esenciales que se reflejan en los cuadros que se incluyen especialmente en cuanto a plazos y costes de ejecución. 

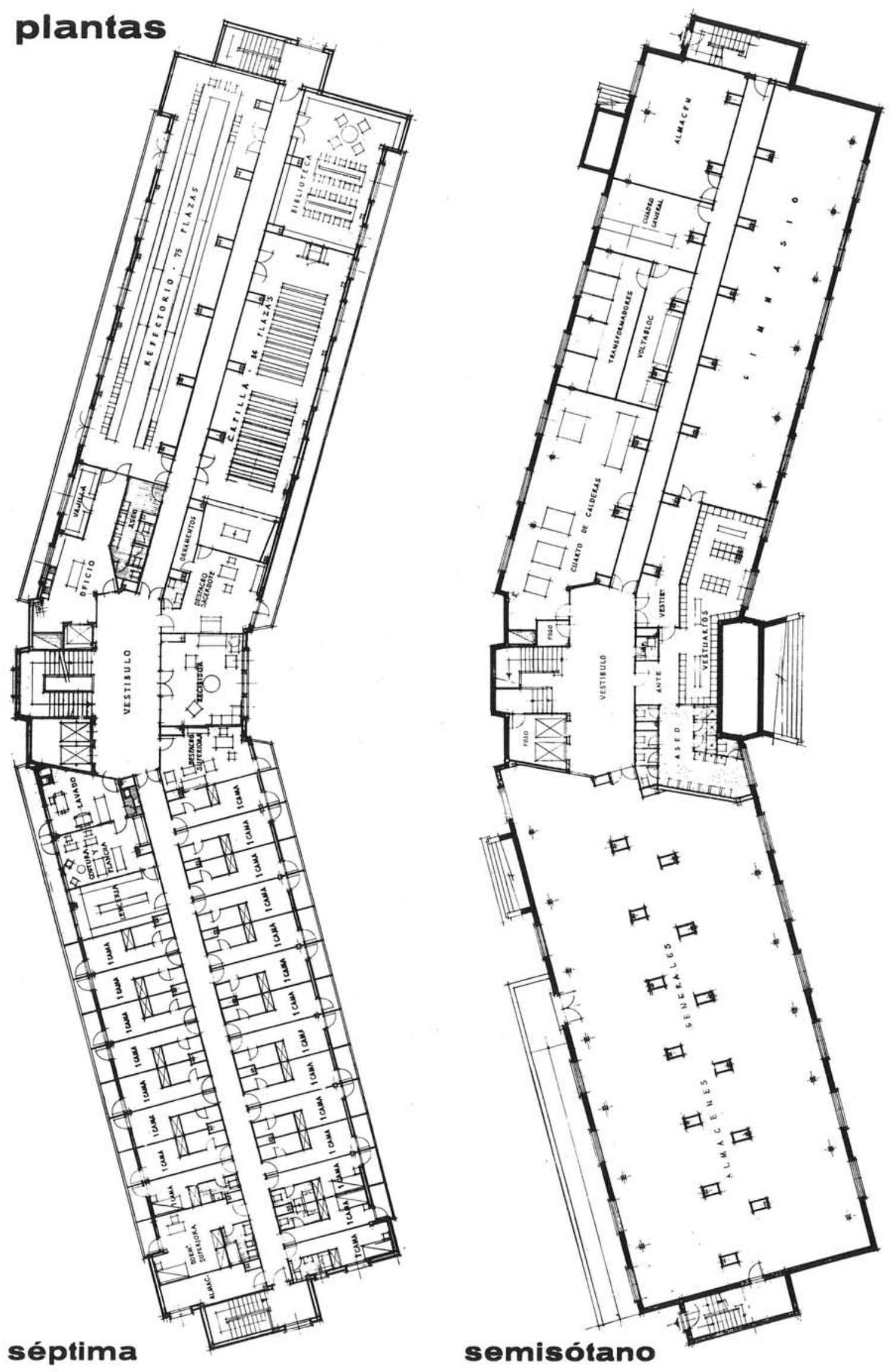


\section{mortuorio y anatomía patológica}

En un edificio independiente hemos situado los servicios de Anatomía Patológica y Necropsias para toda la Ciudad Sanitaria.

El edificio consta de una planta rectangular con un patio interior de fachadas paralelas a las exteriores, con un jardín en dicho patio.

El servicio de necropsias está compuesto por siete salas de duelo con sus correspondientes estancias
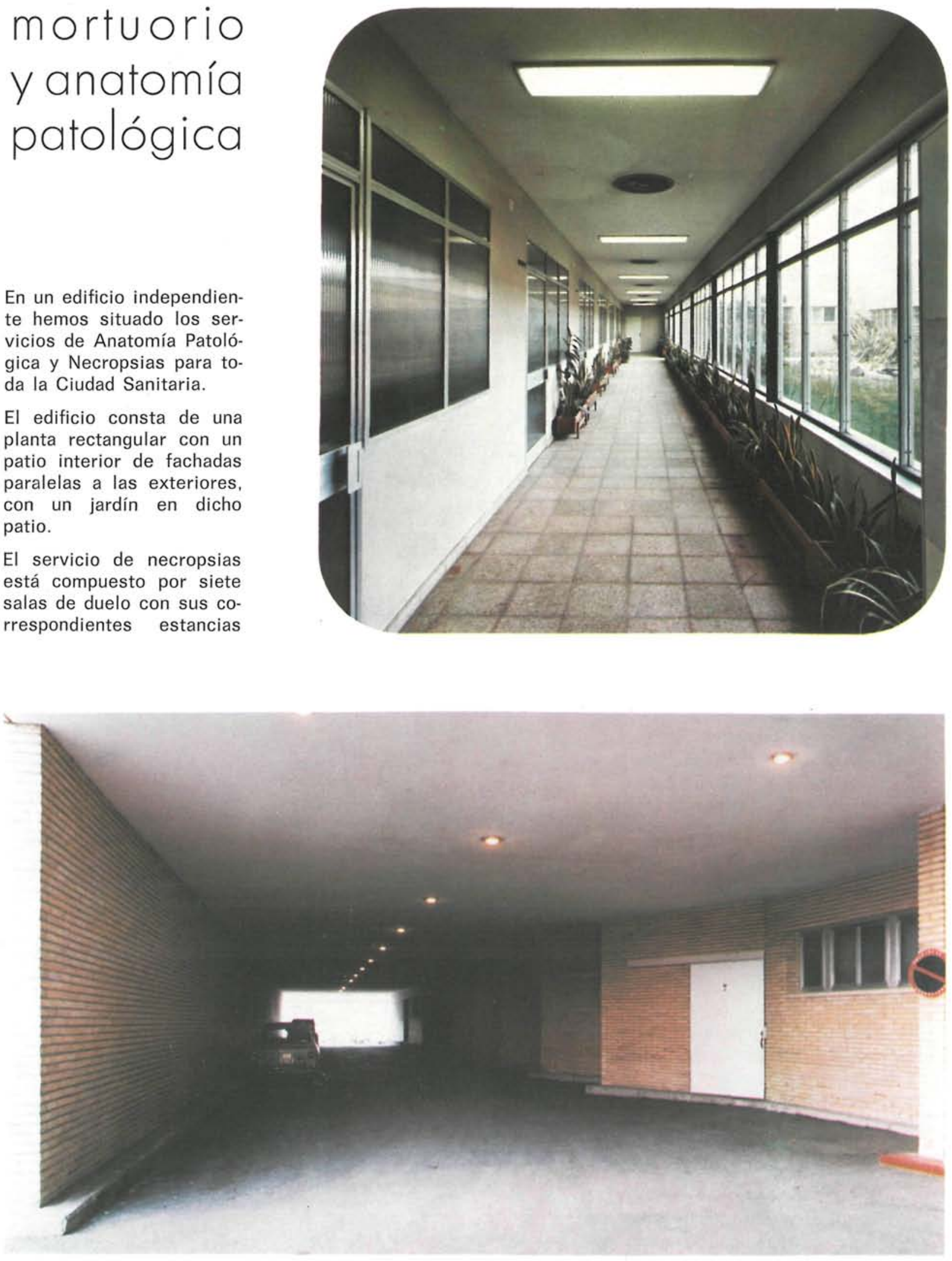


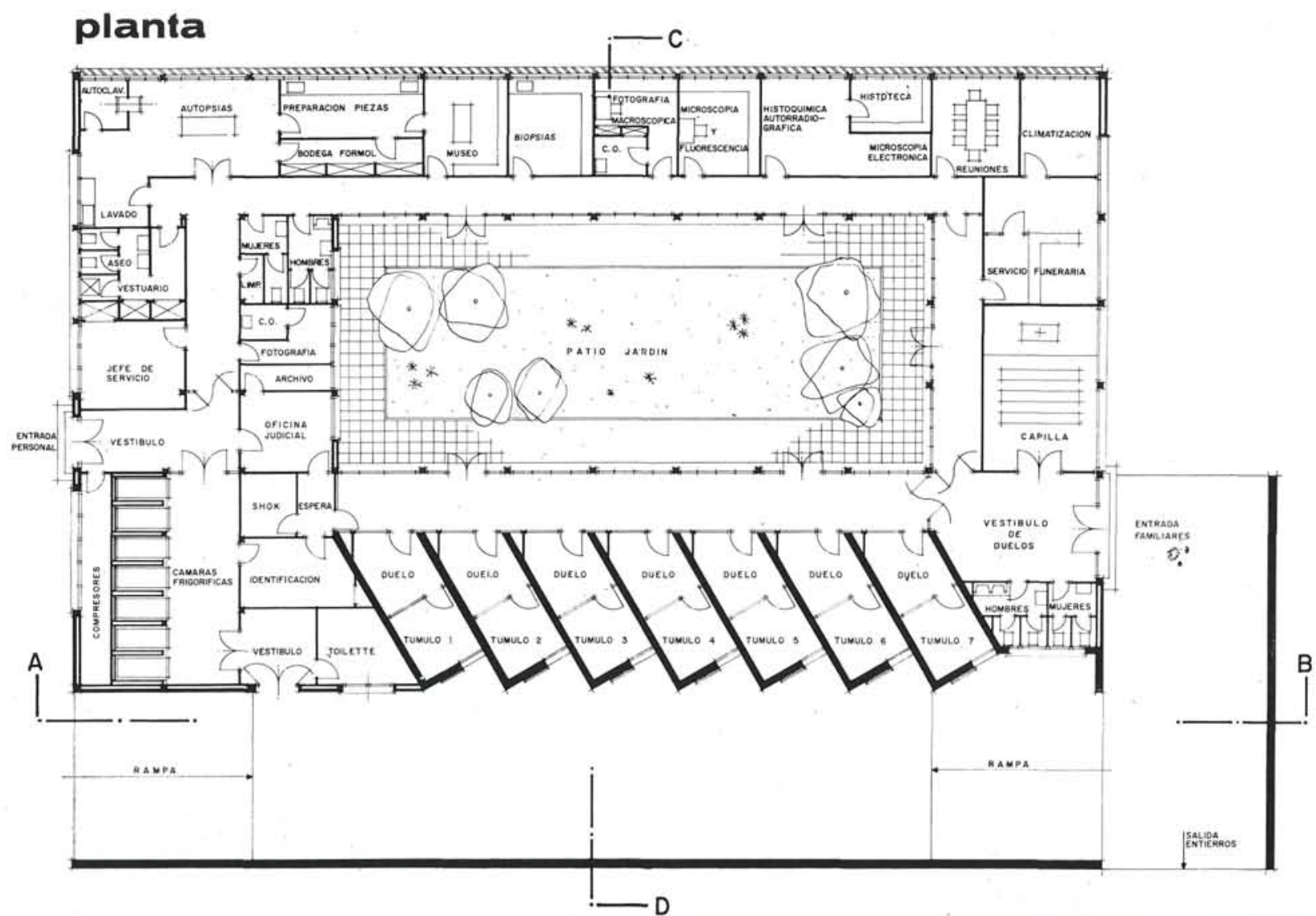

para el túmulo separadas mediante mampara de aluminio con cristal transparente y puerta de unión. Cada una de estas unidades tiene una puerta exterior que comunica con una salida cubierta y permite la organización y salida de los entierros sin que sean vistos por el resto de la Ciudad Sanitaria. Completa el servicio una capilla, una oficina para el servicio de funeraria y una sala con 14 frigoríficos para la conservación de aquellos cadáveres que por alguna razón deban permanecer más tiempo sin enterrar.

El servicio de Anatomía Patológica. con acceso independiente al anterior. está compuesto por una sala de autopsias y los laboratorios de biopsias. fotografía manoscópica y microscópica, hostoquímica y en general todos los necesarios para un buen funcionamiento del servicio.

Como complemento del Servicio, hay una Sala de Reuniones, aseos y despachos para el personal.

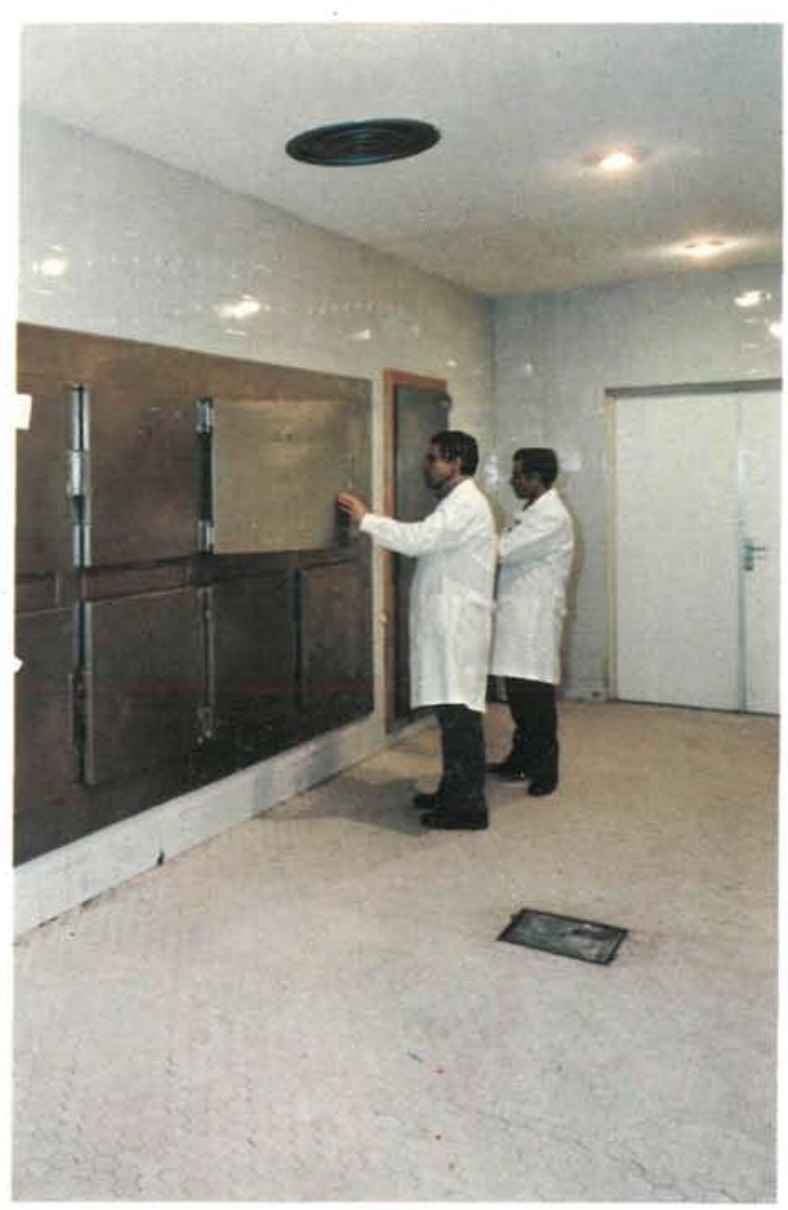




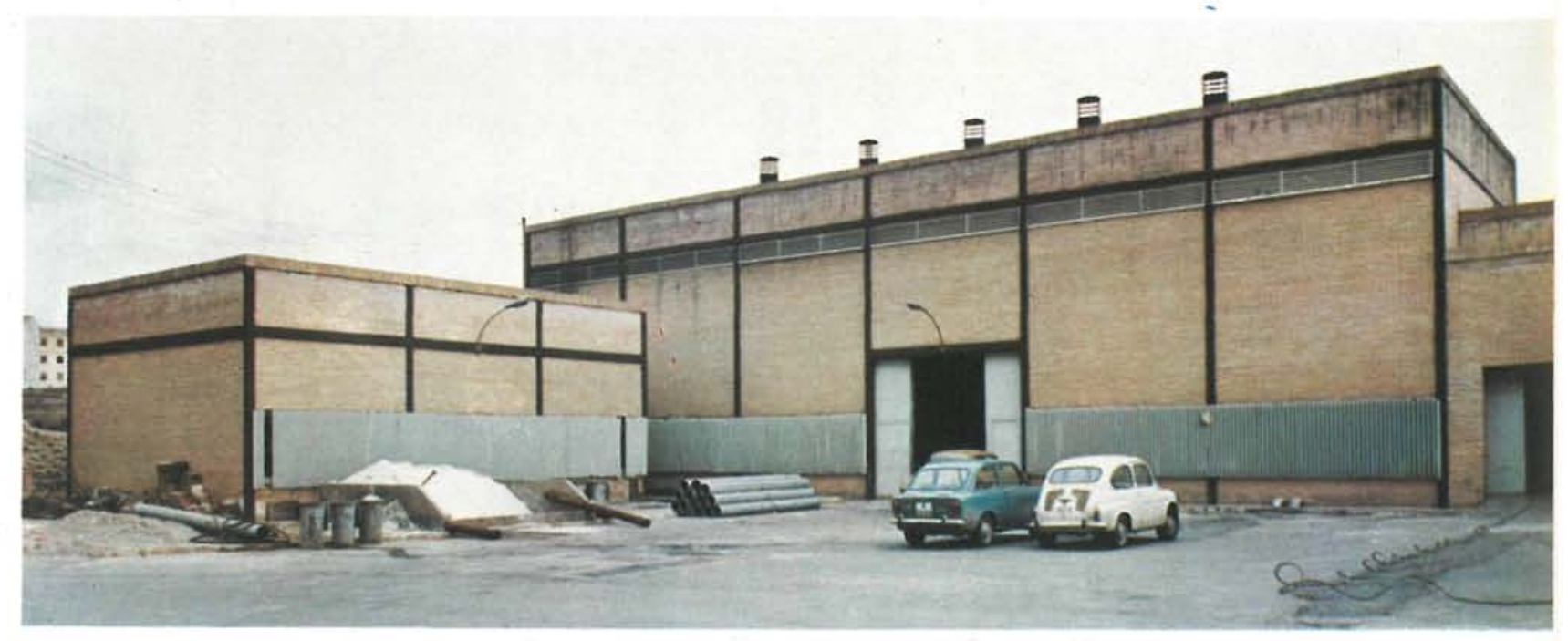

\section{tratamiento de aguas}

Vistas las calidades del agua de la ciudad y la exigencia que las modernas instalaciones requieren, como calderas y equipos de frío, ha sido necesario el montaje de una instalación de descalcificación de agua a base de resina de alta resistencia química y solución de salmuera que nos dé un agua a cero grados. Para conseguir el $\mathrm{pH}$ necesario, hemos colocado un dosificador de fosfato trisódico. Toda la instalación la hemos montado automática para disminuir en lo posible el gasto de personal de mantenimiento.

central térmica y tratamiento de aguas
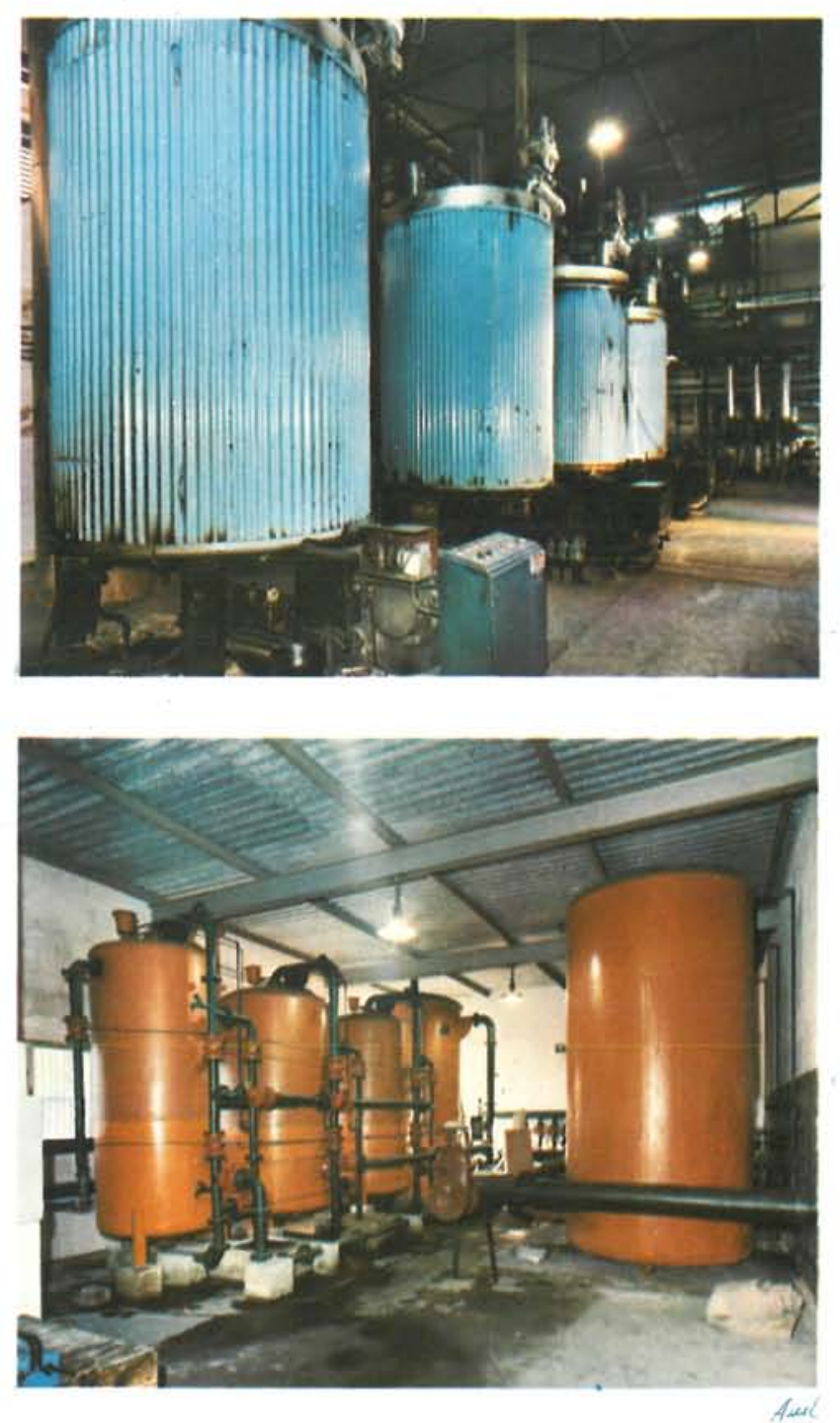


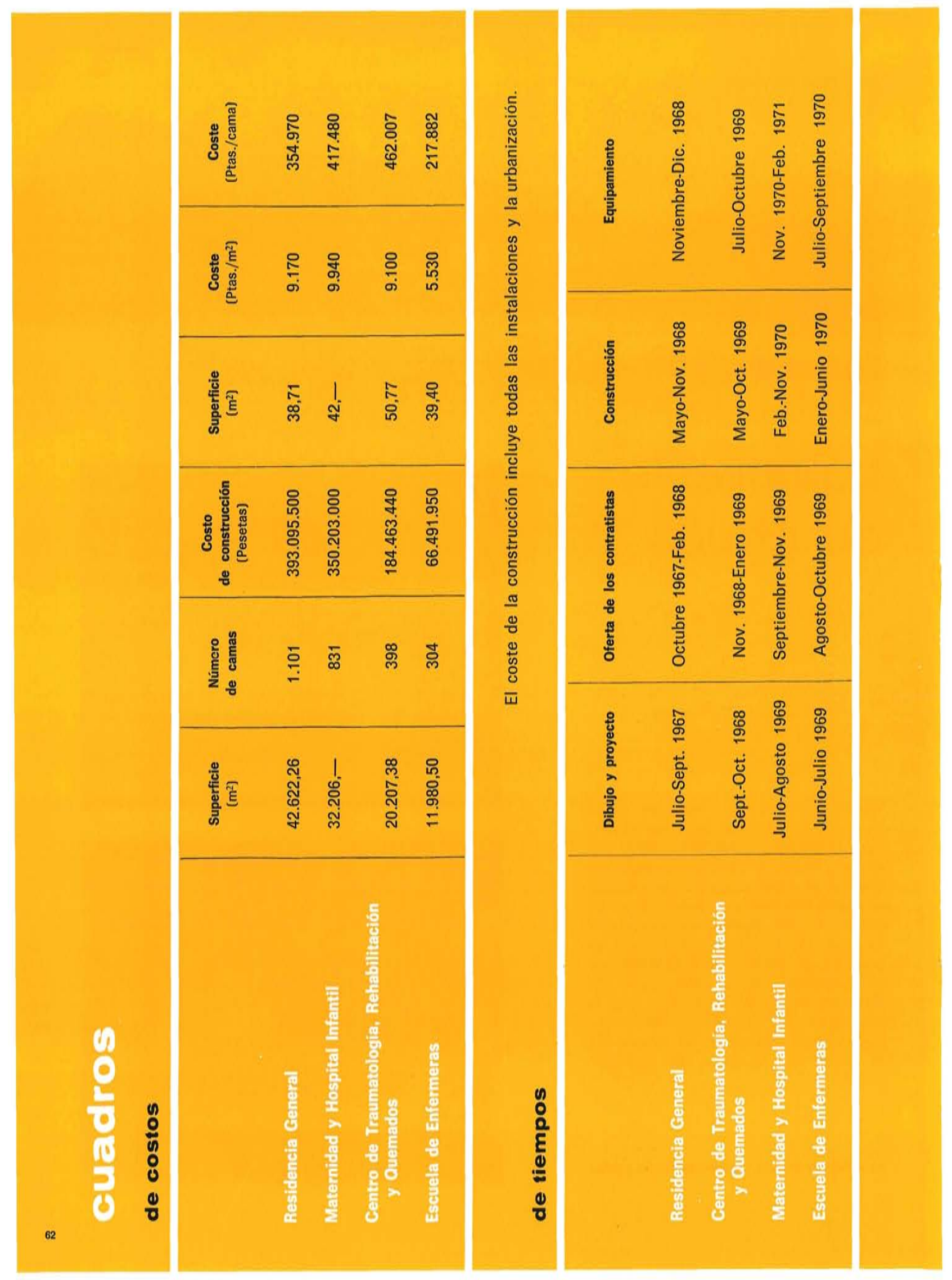




\section{résumé}

Cité sanitaire de la Sécurité sociale "La Fe" - Valence (Espagne)

Architectes: J. de Zavala $\div$ y F. Flórez

Architecte collaborateur dans la direction des travaux: J. Picabea

Cet ensemble sanitaire, construit avec une précision et une rapidité notables, satisfait catégoriquement à toute une série d'exigences urgentes surgies dans la province de Valence. II groupe toutes les expériences antérieurement éprouvées dans des centres similaires en Espagne, avec l'incorpora tion de tout type de progrès techniques, de matériaux et d'installations, qui, d'année en année, sont activement perfectionnés pour ce type d'édifices.

Pour I établissement du projet, les auteurs ont tenu bien compte, pour leur heureuse solution, les conditions essentielles de fonctionnalité, de recherche et d'enseignement. Le programme complet, prévu pour environ 1.100 lits pour malades, comprend sept parties bien différenciées: hôpital pour enfants; école d'infirmières; laboratoires centraux, de recherche et de chirurgie expérimentale, et services géné-

\section{summary}

"La Fe" Social Security Hospital, Valencia

Architects: J. de Zavala $\nmid$ \& F. Flórez

Architect, collaborating in the site management: J. Picabea

This large hospital was built in a notably short time, and all the construction stages were completed in accord with a precise time schedule.

The hospital overcomes in a highly effective manner the urgent need for many medical facilities which were lacking in the Valencia province. The planning of this medical centre incorporates the experience gained in designing similar centres in other parts of the country: it includes every type of technical advance, involvig materials and installations, which, year by year, are being rapidly improved and developed. In the initial design requirements, much emphasis has been given to three basic premisses: functionality, research and training facilities.

The full program for the hospital, which includes 1,100 beds, comprises seven well differentiated zones: the general hos-

\section{zusammenfassung}

Kliniken-Stadt der Sozialversicherung "La Fe» - Valencia

Architekten: J. de Zavala $\dagger$ und F. Flórez

Bei der Bauleitung miterbeitender Architekt: J. Picabea

Mit diesem, mit Präzision und in bemerkenswerter Schnellig keit, erbautem Kliniken-Komplex, wurden endgültig eine Reihe der dringendsten Bedürfnisse der Provinz gelöst. Man verwertete in ihr sämtliche Erfahrungen, die man mit ähnlichen Komplexen im ganzem Land gesammelt hatte, indem man die neuesten technischen Erkenntnisse anwendete, sei es im Bezug auf das Baumaterial, oder auf die Einrichtungen, die sich jährlich in rascher weise bei diesem Gebäudetyp vervollkommnen.

Die besonderen Voraussetzungen die für die Organisation, die Forschungs- und Lehrmöglichkeiten gestellt waren, wurden bei diesem Entwurf besonders beachtet, um eine möghichst günstige Lösung zu erreichen.

Das vollständige Programm, vorgesehen für ca. 1.100 Betten, umfasst sieben verschiedene Gebiete: ein allgemeines Krankenhaus, ein Rehabilitationszentrum, eine Entbindung sanstalt, ein Kinderkrankenhaus, eine Krankenpfegerinnen- raux (centrale thermique, buanderie, incinération, morgue, etc.)

Les auteurs ont soigneusement étudié la chambre type. ayant tendance au maximum de souplesse d'occupation, au minimum relatif de coût, au maximum de confort, aux parcours modérés des infirmières, à la réduction de promiscuité, etc., groupant rationnellement le nombre de celles-ci à servir par un même noyau de services généraux.

Dans trois numéros successifs d'uINFORMES DE LA CONS TRUCCION" sera développé, d'une manière suffisamment expressive, cet important ensemble sanitaire, qui met en évidence l'effort considérable de la Sécurité sociale espagnole pour se mettre au premier plan dans le domaine mon dial de l'assistance sanitaire.

pital; rehabilitation centre; maternity hospital; children's hospital: nurses school: central laboratories for research and experimental surgery; and general services (heating plant, washing department, incineration, mortuory, etc.).

The standard hospital room has been most carefully planned. aiming to achieve maximum adaptability, minimum cost most comfort, optimum circulation facility for the nurses, and least intermixing of various types of patients. The rooms to be attended by the same nucleus of general services have been rationally grouped together.

Three subsequent issues of aINFORMES DE LA CONSTRUC CIONn will describe in considerable detail this important project, which exemplifies the huge effort by the Spanish Health Service to reach the forefront of the world in state hospital facilities.

Labore für Forschungszwecke und experimentelle Chirugie und allgemeine Betriebseinrichtungen (Heizwerke, Wäscherei, Verbrennungsanlagen, Leichenhaus, usw...).

Der Zimmer-Typ wurde sorgfältig ausgedacht, man beachtete dabei eine vielseitige Ausnutzungsmöglichkeit, den geringsten Kostenaufwand, den grösstmöglichen Komfort, günstige aufteilung der Arbeitswege für die Pflegerinnen, leichte Aufteilungsmöglichkeiten, usw..., indem man eine rationelle Gruppierung der Zimmer entwarf, die die Versorgung von einer einzigen Zentrale aus ermöglicht.

In den drei folgenden Ausgaben dieser Zeitschrift wird in einer möglichst bildhaften Darstellung dieser wichtige Bau. komplex beschrieben, welcher die aussergewöhnlichen Anstrengungen der spanischen Allgemeinen Versicherung wiederspiegelt, die sich der modernster Entwicklung in der Welt auf dem Gebiete der sanitären Hilfe anzupassen wünscht. 